\title{
INDUCTION OF MESENCHYMAL STEM CELL DIFFERENTIATION AND CARTILAGE FORMATION BY CROSS-LINKER-FREE COLLAGEN MICROSPHERES
}

\author{
M. Mathieu ${ }^{1,2, *}$, S. Vigier ${ }^{1,4,5}$, M-N. Labour ${ }^{4,5}$, C. Jorgensen ${ }^{1,2,3}$, E. Belamie ${ }^{4,5, \S}$ and D. Noë1 $1^{1,2,}$ \\ ${ }^{1}$ Inserm, U844, Hôpital Saint-Eloi, Montpellier, France \\ ${ }^{2}$ Université Montpellier 1, UFR de Médecine, Montpellier, France \\ ${ }^{3}$ Service d'Immuno-Rhumatologie Thérapeutique, Hôpital Lapeyronie, Montpellier, France \\ ${ }^{4}$ Ecole Pratique des Hautes Etudes, Paris, France \\ ${ }^{5}$ Institut Charles Gerhardt, UMR 5253, Equipe MACS, Ecole Nationale Supérieure de Chimie, Montpellier, France
}

$\S$ Both authors contributed equally

\begin{abstract}
Because of poor self-healing ability, joint cartilage can undergo irreversible degradation in the course of various diseases or after injury. A promising approach for cartilage engineering consists of using of mesenchymal stem cells (MSC) and a differentiation factor combined with an injectable carrier biomaterial. We describe here a novel synthesis route for native collagen microspheres that does not involve the use of potentially toxic crosslinking agents. An emulsion was formed between a type I collagen solution and perfluorinated oil, stabilised by a biocompatible triblock perfluorinated copolymer surfactant. Spherical microparticles of fibrillar collagen were formed through a sol-gel transition induced by ammonia vapours. Electron microscopy observations showed that these self-cross-linked microspheres were constituted by a gel of striated collagen fibrils. Microspheres that were loaded with transforming growth factor beta (TGF- $\beta$ ) 3 progressively released this differentiation factor over a four weeks period. Human MSC rapidly adhered to TGF- $\beta 3$-loaded microspheres and, after $21 \mathrm{~d}$ of culture, exhibited typical chondrocyte morphology and produced an uncalcified matrix made of the predominant cartilage components, aggrecan and type II collagen, but devoid of the hypertrophic marker type X collagen. Subcutaneous co-injection of MSC and TGF- $\beta 3$-loaded microspheres in mice consistently led to the formation of a cartilage-like tissue, which was however hypertrophic, calcified and vascularised. In conclusion, we developed cross-linker free collagen microspheres that allowed chondrogenic differentiation of MSC in vitro and in vivo.
\end{abstract}

Keywords: Biomaterial, cartilage engineering, chondrogenesis, collagen, injectable, mesenchymal stem cell, microspheres, safety, self-assembly, transforming growth factor- $\beta$.

*Address for correspondence:

Marc Mathieu

Inserm U 844

Hôpital Saint-Eloi, INM

80 avenue Augustin Fliche

F-34091 Montpellier cedex 5

France

Telephone Number: +33499636122

FAX Number: +33499636020

E-mail:marc.mathieu@inserm.fr

\section{Introduction}

In joints, articular cartilage functions as a bearing surface between bones. It also allows for smooth motion with low friction and shear stresses between bones, thereby preventing wear. Articular cartilage is frequently injured following trauma or during the course of various diseases, such as osteoarthritis or rheumatoid arthritis. However, due to its poor capacity of regeneration, lesions do not spontaneously heal. There is therefore a high demand for an effective tissue-engineering approach for cartilage repair. Current surgical procedures still encounter limited success, while chondrocyte-based therapies have not yet proven to be superior for the treatment of articular cartilage lesions (Nakamura et al., 2009). Moreover, the clinical use of autologous chondrocytes has been hampered by a number of limitations. In particular, a challenging issue is to expand the cells into very large numbers while maintaining their chondrocytic phenotype, i.e. their ability to produce hyaline cartilage and not fibrous tissue. In these respects, the use of multipotent mesenchymal stromal cells or mesenchymal stem cells (MSC) represents an appealing alternative for cartilage repair. MSC are found in large amounts in the bone marrow or adipose tissue, are isolated using easy and reproducible procedures and they proliferate in vitro (Caplan, 2007). During the past ten years, they have attracted great interest because of their unique characteristics and, in particular, their differentiation potential towards cells belonging to the musculoskeletal lineages, such as osteoblasts, adipocytes and chondrocytes (Caplan, 2007). In addition, MSC secrete a variety of bioactive factors that confer them with immunosuppressive, anti-fibrotic or anti-apoptotic properties that may be of interest for the treatment of rheumatologic disorders (Maumus et al., 2011). Since the first demonstration that MSC can differentiate in vitro into chondrocytes (Johnstone et al., 1998; Mackay et al., 1998), a number of chondrogenic conditions and numerous natural or synthetic scaffolds have been tested (for review, see Vinatier et al., 2009). The favoured strategy consists of developing a material that carries the cells and delivers a soluble factor belonging to the transforming growth factor beta (TGF- $\beta$ ) family. Various members of this family have been shown to be potent inducers of chondrogenesis in vitro and to regulate progression towards hypertrophic chondrocytes, which needs to be avoided for stable cartilage engineering (reviewed in Studer et al., 2012). A progressive release of the differentiation factor from the 
scaffold over the whole differentiation time period seems preferable in order to achieve an optimal chondrogenic effect (Mackay et al., 1998) and avoid osteophyte formation due to high intra-articular concentration of TGF- $\beta$ (van Beuningen et al., 1994).

Here, we have developed a type I collagen-based scaffold because natural polymers have interesting properties in the context of damaged tissue repair, especially cartilage regeneration (Balakrishnan and Banerjee, 2011). Indeed, macromolecules from the extracellular matrix such as collagens are not only biocompatible and biodegradable, but they also provide a biomimetic environment favourable to eliciting a specific cell response (Lutolf et al., 2009) thanks to appropriate mechanical (Engler et al., 2004; Engler et al., 2006; Park et al., 2011) and biochemical cues (Hui et al., 2008; Ode et al., 2010). The major drawback of natural polymers is the possibility of disease transmission. For type I collagen, this safety issue has been addressed by carefully selecting the donor source. As a result, type I collagen-based materials are currently in clinical use for various purposes, including cartilage repair (Crawford et al., 2012), with no major secondary effects reported so far. Moreover, an ultra-rapid isolation procedure for type I collagen has been developed that would enable the use of autologous type I collagen in humans and thus increase overall safety for treated patients (Pacak et al., 2011). Alternatively, recombinant type I collagen (Shoseyov et al., 2013) could be a solution to infection issues, but to date its production remains too expensive for biomedical applications.

For a clinical application in the field of orthopaedic surgery, it is crucial that the biomaterial be injectable since this enables a much less invasive implantation procedure. Many systems developed in recent years for this purpose are based on the in situ gelification of polymers through physical or chemical crosslinking. The main limitations of this approach are: i) the relatively poor mechanical properties of the resulting scaffold; and ii) the difficulty of incorporating an active factor with an extended release profile. In the particular case of encapsulation in loose $3 \mathrm{D}$ collagen scaffolds, the immobilised cells have a tendency to first contract the matrix around them for as long as two weeks (Bell et al., 1979; Li et al., 2011), before engaging into a specific differentiation process. To circumvent these drawbacks of existing implantable hydrogels, porous microparticles acting both as local reservoirs of active factors and as cell carriers have been developed. However, most collagen- or gelatin-based microspheres reported so far have been treated with chemical cross linkers to strengthen and stabilise their structure (Han et al., 2010; Rossler et al., 1995; Solorio et al., 2012). We believe that it is preferable to avoid chemical cross linkers, since these have various unwanted effects. Conventional cross-linking techniques have clearly been shown to alter recognition of gelatin or collagen by integrins and reduce cell adhesiveness (Grover et al., 2012). Importantly, binding through integrins promotes not only cell adhesion (Durr et al., 1993), but also chondrogenic differentiation (Segat et al., 2002). Secondly, residual cross linker could affect the biological activity of growth factors incorporated into the microspheres as well as cell growth and adhesiveness
(Speer et al., 1980; Wiebe et al., 1988). In addition, in the long term, cytotoxicity due to release of cross linker from the implant cannot be ruled out. Collagen microspheres devoid of chemical cross linker have been previously described, but these were unstable over time and were obtained by a very tedious technique, i.e. manually pipetting micro-volumes to produce the beads individually, that would be difficult to scale up (Hui et al., 2008; Li et al., 2011).

With these issues in mind, we report here a novel method for the preparation of cross-linker-free type I collagen microspheres. An emulsion was prepared with an acidic collagen solution, and stabilised by a custom-synthesised biocompatible perfluorinated triblock copolymer for which we propose a simplified straightforward one-step synthesis protocol. We found that this emulsion composition was the only one able to withstand the diffusion of ammonia vapour used to neutralise the collagen solution and stabilise the microspheres without chemical cross linking. We then used these collagen-based microspheres as an efficient reservoir for TGF- $\beta 3$ and as a carrier for MSC to promote their differentiation into chondrocytes in vitro. Finally, we investigated how such active micro-carriers associated with MSC could elicit the formation of cartilage at ectopic sites in vivo.

\section{Materials and Methods}

\section{Triblock co-polymer surfactant synthesis}

The synthesis of the surfactant was adapted from previous works (Hamdoune et al., 2000; Holtze et al., 2008; Zhu et al., 2005) and simplified. It consists in coupling perfluorinated polyether tails (Krytox $157 \mathrm{FSH}, 7500 \mathrm{~g} /$ mol, DuPont, Wilmington, DE, USA) at both ends of a polyethylene glycol diamine moiety (PEG $1500 \mathrm{~g} / \mathrm{mol}$ ) by the formation of amide bonds with the carboxylic endgroup of Krytox. The molecular weight of both blocks was chosen based on the work by Holtze et al. (Holtze et al., 2008) and the commercial availability of the products. The biocompatibility of non-ionic surfactants formed by such coupling has been reported in the literature (Clausell-Tormos et al., 2008; Holtze et al., 2008). All chemicals were purchased from Sigma-Aldrich (St. Louis, MO, USA), unless otherwise noted. All solvents were reagent grade and used without further purification. To avoid the presence of water, all solvents were distilled and anhydrous, and reactions performed under argon. Krytox $\left(7.20 \times 10^{-4}\right.$ mole) was first mixed with $35 \mathrm{~mL}$ of distilled perfluorinated oil (3M Novec HFE 7500, $3 \mathrm{M}$, St. Paul, MN, USA), before PEG (3.33 x 10-4 mole, dissolved in $15 \mathrm{~mL}$ of anhydrous tetrahydrofurane, THF) and 4-methylmorpholine (1.33 x $10^{-3}$ mole $)$ were added. The mixture was stirred at low temperature $\left(-10^{\circ} \mathrm{C}\right)$ in a $\mathrm{NaCl} /$ ice mixture $(33 \mathrm{~g} / 100 \mathrm{~g})$. The reaction was initiated by the drop-wise addition of isoprenyl chloroformate $\left(1.33 \times 10^{-3} \mathrm{~mole}\right)$. The mixture was kept cold overnight, then allowed to warm back to room temperature, and heated to $40{ }^{\circ} \mathrm{C}$ for $15 \mathrm{~min}$. The last step resulted in a macroscopic liquid/solid phase separation. The surfactant mostly present in the liquid phase was collected with a 
syringe and purified by removing acetone formed as a byproduct and THF, by evaporation under vacuum at $55^{\circ} \mathrm{C}$. Remaining HFE 7500 can be evaporated at $80^{\circ} \mathrm{C}$ to obtain the concentrated liquid surfactant. The reaction between the amine end-groups of polyethylene glycol diamine and the carboxylic groups of Krytox was followed by Fourier Transform Infrared Spectroscopy (FTIR) by the apparition of a strong absorption band at $1688 \mathrm{~cm}^{-1}$ characteristic of amide bond formation, along with the disappearance of the band at $1774 \mathrm{~cm}^{-1}$ attributed to the carboxylic group of Krytox. Although it may contain a mixture of di- and tri-block copolymers, the synthesised surfactant proved efficient to form stable emulsions and to obtain collagen microspheres, and was used without further purification.

\section{Collagen microspheres preparation and characterisation}

Collagen microspheres were obtained from an acidic type I collagen solution by a water-in-oil emulsion process. Type I collagen was purified from rat tail tendons following a procedure described elsewhere (Gobeaux et $a l ., 2008)$. Briefly, frozen rat tails were thawed in ethanol and dissected in a sterile hood. The tendons were pulled out and rinsed with phosphate buffered saline (PBS), then treated with $4 \mathrm{M} \mathrm{NaCl}$, rinsed again with $\mathrm{PBS}$ and finally dissolved in $500 \mathrm{mM}$ acetic acid. Proteins other than type I collagen were removed by cycles of selective precipitation and centrifugation. The resulting collagen solutions were thoroughly dialysed against $500 \mathrm{mM}$ acetic acid and clarified at $41,000 \mathrm{x} g$ for $4 \mathrm{~h}$ to remove remaining aggregates. The dilute collagen solutions were then brought to their final concentration by dialysis against PEG $(2 \mathrm{x}$ $10^{4} \mathrm{~g} / \mathrm{mol}$ ) solutions at $50 \mathrm{mg} / \mathrm{mL}$ in $500 \mathrm{mM}$ acetic acid. Collagen concentration was determined by assessing the amount of hydroxyproline (Bergman and Loxley, 1963). The emulsion was formed in a silanised (Sigmacote, SigmaAldrich) glass vial by mixing $2.7 \mathrm{~mL}$ of perfluorinated oil HFE-7500, $300 \mu \mathrm{L}$ of copolymer surfactant at $10 \%$ in HFE-7500 and $1 \mathrm{~mL}$ of a $9 \mathrm{mg} / \mathrm{mL}$ acidic collagen solution under vigorous stirring. The stable emulsion thus obtained was placed overnight under ammonia vapours in a closed container. Collagen microspheres were then floated off from the emulsion and washed with PBS at least three times by dispersion/centrifugation ( $100 \mathrm{~g}, 20 \mathrm{~min})$ cycles. These microspheres could be kept intact for at least 3 months at room temperature (RT) under constant rotational agitation. The size distribution of collagen microspheres was determined by optical measurements of the diameters (Leica DM2500, LAS EZ software, Leica, Wetzlar, Germany) from five independent syntheses $\left(\mathrm{n}_{\text {tot }}=1214\right.$, $\left.\mathrm{n}_{\mathrm{ave}}=243\right)$.

For scanning electron microscopy observations, collagen microspheres were pelleted by centrifugation (100 x $g, 20 \mathrm{~min}$ ), fixed by immersion in a glutaraldehyde solution $(2.5 \%$ in PBS ) for $1 \mathrm{~h}$ at ambient temperature and dehydrated in water/ethanol mixtures $(10 \%, 30 \%, 50 \%$, $70 \%$ and $100 \%$ ethanol). Samples were then supercritically dried with $\mathrm{CO}_{2}$ (E3100 Polaron Critical Point drier, Quorum Technologies, Laughton, UK). After platinumsputter coating (Balzers SCD 020, Balzers, Liechtenstein), observations were carried out in the secondary electron mode with a scanning electron microscope (Hitachi 4800 S, Hitachi, Tokyo, Japan) operated at an accelerating voltage of $50 \mathrm{kV}$. For transmission electron microscopy, microspheres were pelleted, fixed and dried as above. The samples were then embedded in a resin and observed after ultrathin sectioning ( $70 \mathrm{~nm}$ thick sections) on a JEOL 1200 EX2 microscope (JEOL, Tokyo, Japan) operating at $100 \mathrm{kV}$.

\section{Impregnation of the microspheres with TGF- $\beta 3$}

Impregnation of the microspheres was performed with TGF- $\beta 3$, because this factor is reported to have a higher chondrogenic potential than TGF- $\beta 1$ (Barry et al., 2001). The amount of TGF- $\beta 3$ used for impregnation was equal to the total amount of TGF- $\beta 3$ added when MSC are induced into chondrogenic differentiation by the usual micromass culture. TGF- $\beta 3$ (R\&D Systems, Minneapolis, MN, USA) was initially reconstituted at $100 \mathrm{ng} / \mu \mathrm{L}$ with $4 \mathrm{mM}$ hydrochloric acid containing $1 \mu \mathrm{g} / \mu \mathrm{L}$ bovine serum albumin (BSA, Sigma-Aldrich) as recommended by the manufacturer and was then diluted to $50 \mathrm{ng} / \mu \mathrm{L}$ with incomplete chondrogenic medium consisting of Dulbecco's Modified Eagle's Medium (DMEM) supplemented with $0.1 \mu \mathrm{M}$ dexamethasone, $0.17 \mathrm{mM}$ ascorbic acid and $1 \%$ insulin-transferrin-sodium selenite to obtain a solution at $\mathrm{pH}$ 6. This solution was used to infuse pelleted microspheres at RT for $16 \mathrm{~h}$ at a ratio of $1 \mu \mathrm{L}(50 \mathrm{ng})$ per 100 microspheres. In these conditions, the TGF- $\beta 3$ solution was entirely adsorbed by the microspheres.

\section{In vitro release of bioactive TGF- $\beta 3$}

The release profile of TGF- $\beta 3$ from one hundred microspheres was determined in 24-well plates with ultralow attachment surface (Costar, Cambridge, MA, USA) containing $500 \mu \mathrm{L}$ of incomplete chondrogenic medium. Incubation was carried out at $37^{\circ} \mathrm{C}$ and at various time intervals, $100 \mu \mathrm{L}$ of supernatant were collected and replaced by fresh medium. Bioactivity of the released TGF- $\beta 3$ was assessed with an assay developed by Tesseur et al. (Tesseur et al., 2006). This assay uses mouse fibroblasts (MFB-F11) isolated from TGF- $\beta 1$ (-/-) mice and stably transfected with a reporter plasmid consisting of TGF- $\beta$ responsive Smad-binding elements coupled to the secreted alkaline phosphatase (SEAP) gene. Cells were seeded at $3 \times 10^{4}$ cells/well in 96-well culture plates containing DMEM and $10 \%$ foetal calf serum (FCS). After overnight incubation, cells were washed twice with PBS and incubated in $50 \mu \mathrm{L}$ of DMEM without serum. After $2 \mathrm{~h}, 50 \mu \mathrm{L}$ of test sample was added to the cells for $24 \mathrm{~h}$. A standard curve was established using serial dilution of recombinant TGF- $\beta 3$. Activity of SEAP was measured in $50 \mu \mathrm{L}$ of culture supernatant using the SEAP reporter gene assay, chemiluminescent kit (Roche Diagnostics, Mannheim, Germany) and a Wallac 1450 MicroBeta Trilux luminescence counter (Wallac Oy, Turku, Finland).

\section{Isolation of MSC}

Primary human MSC were isolated from two patients after written informed consent and approval by the General Direction for Research and Innovation, the Ethics Committee from the French Ministry of Higher 
Table 1. Primers used for qPCR analyses.

\begin{tabular}{|l|l|l|l|}
\hline Gene & $\begin{array}{l}\text { NCBI } \\
\text { accession }\end{array}$ & Sense Primer & Antisense Primer \\
\hline ACAN* & NM_013227 & TCGAGGACAGCGAGGCC & TCGAGGGTGTAGCGTGTAGAGA \\
\hline COL2A1** & NM_033150 & CAGACGCTGGTGCTGCT & TCCTGGTTGCCGGACAT \\
\hline COL10A1 & NM_000493 & TGCTGCCACAAATACCCTTT & GTGGACCAGGAGTACCTTGC \\
\hline COMP & NM_000095 & CCGACAGCAACGTGGTCTT & CAGGTTGGCCCAGATGATG \\
\hline HAPLN1 & NM_001884 & TTCCACAAGCACAAACTTTACACAT & GTGAAACTGAGTTTGTATAACCTCTCAGT \\
\hline RPS9 & NM_001013 & GATTACATCCTGGGCCTGAA & ATGAAGGACGGGATGTTCAC \\
\hline SPP1* & NM_000582 & CTCCATTGACTCGAACGACTC & CAGGTCTGCGAAACTTCTTAGAT \\
\hline
\end{tabular}

${ }^{1}$ Abbreviations used: ACAN, aggrecan; COL2A1, alpha-1 type II collagen; COL10A1, alpha-1 type X collagen; COMP, cartilage oligomeric matrix protein; HAPLN1, hyaluronan and proteoglycan link protein 1; RPS9, ribosomal protein S9; SPP1, secreted phosphoprotein 1/osteopontin.

* All known transcript variants were amplified.

** Only transcript variant 2 was amplified.

Education and Research (registration number: DC-20091052). MSC were isolated from bone marrow aspirates of patients undergoing hip replacement surgery, as previously described (Djouad et al., 2005). Briefly, cell suspensions were plated in $\alpha$-MEM supplemented with $10 \% \mathrm{FCS}, 1 \mathrm{ng} /$ $\mathrm{mL}$ fibroblast growth factor 2 (FGF2) (R\&D Systems), $2 \mathrm{mM}$ L-glutamine, $100 \mathrm{U} / \mathrm{mL}$ penicillin and $100 \mu \mathrm{g} / \mathrm{mL}$ streptomycin. For expansion, MSC were subcultured at a density of 1000 cells $/ \mathrm{cm}^{2}$. These were shown to be positive for CD44, CD73, CD90 and CD105 and negative for CD14, CD34 and CD45 and used at the third or fourth passage.

\section{Cell culture with the microspheres and induction of differentiation in vitro}

Cells were mixed with microspheres and seeded in 24well plates with ultra-low attachment surface. 250,000 cells were combined with 100 microspheres in each well, corresponding to an attachment surface on the microspheres of $180 \mu \mathrm{m}^{2}$ per cell. In this setup, cell confluence was reached as soon as the cells had adhered to the microspheres. Control cultures were performed with cells alone, i.e. in the absence of microspheres. Cells were cultured for 21 to $28 \mathrm{~d}$ in incomplete chondrogenic medium. When cells were cultured alone, the medium was supplemented with $10 \mathrm{ng} / \mathrm{mL}$ TGF- $\beta 3$ (condition MSC+TGF). When cells were cultured with unloaded or TGF- $\beta 3$-loaded microspheres, the medium was not supplemented with TGF- $\beta 3$ (conditions $\mathrm{mS}+\mathrm{MSC}$ and $\mathrm{mS} / \mathrm{TGF}+\mathrm{MSC}$, respectively). The medium was replaced twice a week.

\section{RNA extraction, reverse transcription and quantitative PCR}

Total RNA was isolated using RNeasy mini kit (Qiagen, Venlo, Netherlands) and reverse-transcribed using GeneAmp Gold RNA PCR Core kit (Applied Biosystems, Foster City, CA, USA). Quantitative PCR (qPCR) was performed using LightCycler 480 SYBR Green I Master mix and real-time PCR instrument (Roche Diagnostics). PCR conditions were $95{ }^{\circ} \mathrm{C}$ for $5 \mathrm{~min}$ followed by 40 cycles of $15 \mathrm{~s}$ at $95^{\circ} \mathrm{C}, 10 \mathrm{~s}$ at $64{ }^{\circ} \mathrm{C}$ and $20 \mathrm{~s}$ at $72{ }^{\circ} \mathrm{C}$.
For each reaction, a single amplicon with the expected melting temperature was obtained. Primer pairs are listed in Table 1 . These were designed using the web based applications, Primer3 (Rozen and Skaletsky, 2000) and BLAST at the National Center for Biotechnology Information. Of note, for alpha-1 type II collagen, primers amplify only transcript variant 2 , which is the splice form specifically expressed by mature chondrocytes. Expression of the house-keeping gene encoding ribosomal protein S9 (RPS9) was measured for normalisation. The threshold cycle $(\mathrm{Ct})$ of each amplification curve was calculated by Roche's LightCycler 480 software using the second derivative maximum method. The relative amount of a given mRNA was calculated using the $\Delta \Delta \mathrm{Ct}$ method (Livak and Schmittgen, 2001).

\section{Subcutaneous implantation in SCID mice}

$\mathrm{SCID} / \mathrm{Bg}$ mice were grown in our animal facilities and cared for according to the Laboratory Animal Care guidelines. The protocol was approved by the Committee on the Ethics of Animal Experiments in LanguedocRoussillon (CEEA-LR 36) (Permit Number: CEEALR-1042). One hundred microspheres loaded, or not, with TGF- $\beta 3$ were mixed for $2 \mathrm{~h}$ with $2.5 \times 10^{5}$ cells in $100 \mu \mathrm{L}$ of PBS containing sodium carboxymethylcellulose $(0.125 \%$ $\mathrm{w} / \mathrm{v})$, polysorbate $80(0.125 \% \mathrm{w} / \mathrm{v})$ and mannitol $(0.5 \%$ $\mathrm{w} / \mathrm{v})$. The complexes were then injected subcutaneously at two sites on the back of five 18-week-old male SCID mice ( $n=10$ injection sites per group). Twenty one days after implantation, mice were euthanised and inspected for the formation of a neotissue resembling cartilage at sites of injection, i.e. a neotissue that formed a solid lump under the skin and which had after dissection a white-opaque aspect similar to native cartilage. These were processed for histology and immunohistochemical analysis.

\section{Histology and immunohistochemistry}

Samples were fixed with $4 \%$ paraformaldehyde and embedded in paraffin using standard procedures. Serial sections of $4 \mu \mathrm{m}$ thickness were deparaffinised and subjected to histological staining or stained by the 
Fig. 1. Optical and electron microscopic observations of collagen microspheres prepared in emulsion. (a) Bright field view and (b) polarised light views revealing the strong birefringence of the particles. Bar $=200 \mu \mathrm{m}$. (c) Scanning electron microscopy of the microsphere surface. Bar $=50 \mu \mathrm{m}$. Surface closeup shown in inset; the bar is $1 \mu \mathrm{m}$. (d) Transmission electron microscopy showing the internal structure of microspheres with native banded collagen fibrils. Bar $=500 \mathrm{~nm}$.
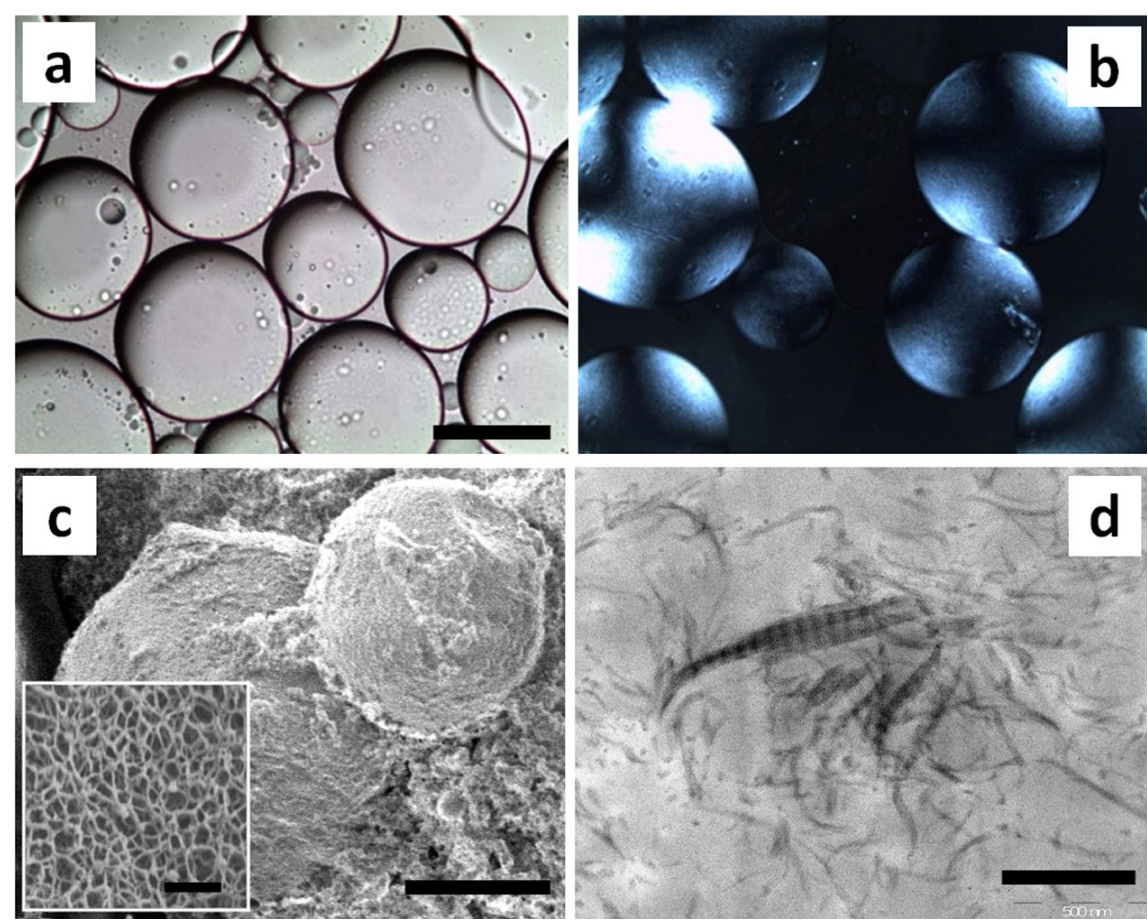

avidin-biotin-peroxidase method for immunodetection with antibodies to type II collagen (clone II-4C11, Acris Antibodies, Herford, Germany), aggrecan (AB1031, Merck Millipore, Billerica, MA, USA), type X collagen (clone X53, Quartett, Berlin, Germany) and human mitochondria (clone MTC02, Thermo Fisher Scientific, Rockford, IL, USA), which were used at a 1/50, 1/1000, 1/10 and 1/500 dilution, respectively. Negative controls to check for background labelling were performed by omitting the primary antibodies or replacing them with non-immune IgG. Prior to incubation with anti-type II collagen and anti-aggrecan antibodies, epitope unmasking was carried out by hyaluronidase treatment for $1 \mathrm{~h}$ at $37^{\circ} \mathrm{C}$. Prior to incubation with anti-human mitochondria antibodies, antigen unmasking was performed by treatment with $1 \mathrm{mM}$ EDTA, $0.05 \%$ Tween 20, pH 8.0 for $19 \mathrm{~min}$ at $98{ }^{\circ} \mathrm{C}$. Reactions were visualised with the chromogenic substrate 3,3'-diaminobenzidine (DAB) followed by haematoxylin counterstaining or, for type $\mathrm{X}$ collagen, with nickel-enhanced DAB followed by eosin counterstaining. Mineralised tissues were stained using the Von Kossa procedure. Sections were treated with $1 \%$ silver nitrate for $5 \mathrm{~min}$, followed by washing in distilled water for 10 min, incubated with $5 \%$ sodium carbonate in $10 \%$ formaldehyde for $5 \mathrm{~min}$ and washed in tap water for $10 \mathrm{~min}$. Unreacted silver was removed with $5 \%$ sodium thiosulphate for $5 \mathrm{~min}$. After a wash in tap water for $10 \mathrm{~min}$, slides were counterstained with $2 \%$ eosin.

\section{Statistical analysis}

The relative levels of a given mRNA between the various treatment groups were compared by one-way analysis of variance (ANOVA) followed by Tukey's post hoc multiple comparisons test or by the Kruskal-Wallis test followed by the Dunn's post hoc multiple comparisons test, when appropriate. Fisher's exact test was used to compare occurrence of neotissue formation in vivo. Statistical significance was set up at $p<0.05$. Analyses were performed with the GraphPad Prism version $6.0 \mathrm{~b}$ for Mac (GraphPad Software, La Jolla, CA, USA).

\section{Results}

\section{Structure and size of the collagen microspheres}

The particles obtained from the perfluorinated emulsion exposed to ammonia vapours appeared round and smooth, and mostly transparent (Fig. 1a). However, observations in polarised light revealed a strong birefringence (Fig. 1b) arising from the self-assembly of collagen triple helices into locally aligned fibrils (Gobeaux et al., 2008). The fibrillar nature and spherical shape of collagen particles was confirmed by scanning electron microscopy (Fig. 1c and inset). Transmission electron microscopy of ultra-sectioned microspheres showed that the matrix is comprised of an interconnected network of very small (10-15 nm) fibrils, and larger ones ( $\sim 50 \mathrm{~nm}$ wide) clearly exhibiting the native $67 \mathrm{~nm}$ striation (Fig. 1d). Fibrils occupy approximately $1 \%$ of the total volume forming an entangled network with 1 to $10 \mu \mathrm{m}$ pores. It should be noted that all attempts to obtain microspheres with the same process, but using other oil/ surfactant couples, were unsuccessful. In most cases, the emulsion would form but eventually break down under ammonia vapours. Similarly, emulsions formed with the perfluorinated precursor Krytox instead of the customsynthesised surfactant did not yield uniform spherical particles. The particles size distribution, determined directly from microscopic images (Fig. 2), gave a median diameter of $300 \pm 67 \mu \mathrm{m}$ by averaging measurements over 5 independent syntheses. 


\section{In vitro release of bioactive TGF- $\beta 3$}

Pelleted microspheres were loaded with TGF- $\beta 3$ following a simple impregnation procedure, during which the solution of TGF- $\beta 3$ was entirely adsorbed by the biomaterial. One hundred microspheres imbued with $50 \mathrm{ng}$ of TGF- $\beta 3$ were distributed in each well and the cumulative release of bioactive TGF- $\beta 3$ was then measured over $28 \mathrm{~d}$ using a reporter gene assay. Data indicated that the scaffold progressively released the differentiation factor over the whole time period analysed (Fig. 3). The proportion of non-incorporated TGF- $\beta 3$ present in the interstitial fluid was included in the total amount measured at day 2 on the release curve, which was approximately $7 \mathrm{ng}$. Thus, at least $43 \mathrm{ng}$ of TGF- $\beta 3$ were loaded into the microspheres - corresponding to a loading efficiency of $86 \%$. An accelerated release occurred from day 16 , and at day 28 approximately half of the loaded TGF- $\beta 3$ had been released. However, the release curve did not plateau, suggesting that the progressive diffusion of bioactive TGF- $\beta 3$ from the scaffold would have probably continued.

\section{Adhesion of MSC on microspheres and in vitro chondrogenic differentiation}

MSC were cultured in incomplete chondrogenic medium with TGF- $\beta 3$-loaded microspheres $(\mathrm{MSC}+\mathrm{mS} / \mathrm{TGF})$ on plates with an ultra-low attachment surface. Two hours later, most of the cells were attached to the microspheres, which had started to aggregate into small clusters using cell bridges. Eventually, a single cluster was formed over time, with a particularly dense and opaque appearance at day 21 or day 28 (Fig. 4a, left panels and Fig. 6c). Progressive formation of similar aggregates was also observed when MSC were cultured with unloaded microspheres (MSC $+\mathrm{mS})$ (Fig. 4a, right panels). When cells were cultured in the absence of microspheres, they also eventually formed micromasses (Fig. 4b, left panel). TGF$\beta 3$-loaded microspheres incubated in the absence of cells (mS/TGF) remained intact and did not form aggregating complexes (Figure 4b, right panel). Expression of several chondrogenic markers, namely aggrecan (ACAN), variant 2 of alpha- 1 type II collagen (COL2A1), cartilage oligomeric matrix protein (COMP) and hyaluronan and proteoglycan link protein 1 (HAPLN1) was analysed by reverse transcription (RT)-qPCR (Fig. 5a-d). When compared to undifferentiated cells (MSC at day 0 ), MSC cultured for $21 \mathrm{~d}$ with unloaded microspheres $(\mathrm{MSC}+\mathrm{mS})$ did not show any induction of these markers. Expression of COL2A1, COMP and HAPLN1 was up-regulated in $\mathrm{MSC}+\mathrm{mS} / \mathrm{TGF}$ as compared to $\mathrm{MSC}$ at day 0 or $\mathrm{MSC}+\mathrm{mS}$, indicating differentiation into mature chondrocytes. As usually observed with human MSC, expression of ACAN was relatively high in undifferentiated cells (Mwale et al., 2006). Nevertheless, the level of ACAN mRNA was higher in $\mathrm{MSC}+\mathrm{mS} / \mathrm{TGF}$ than in $\mathrm{MSC}+\mathrm{mS}$, confirming the differentiated phenotype in the former condition. Cells differentiated equally well when cultured without scaffold but in the presence of TGF- $\beta 3$ in the medium (MSC+TGF), which is the condition that we used as positive control. The hypertrophy markers type X collagen (COL10A1) and secreted phosphoprotein 1/osteopontin (SPP1) were also induced in $\mathrm{MSC}+\mathrm{mS} / \mathrm{TGF}$ at a similar level to that in

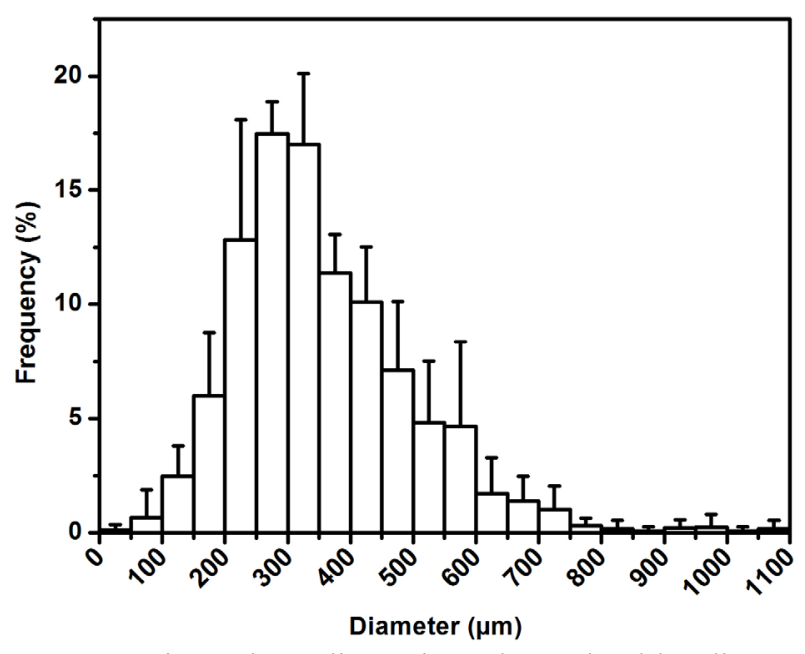

Fig. 2. Microsphere dimensions determined by direct measurements in optical microscopy. Data were averaged over five independent experiments and are represented as mean $\pm \mathrm{SD}$.

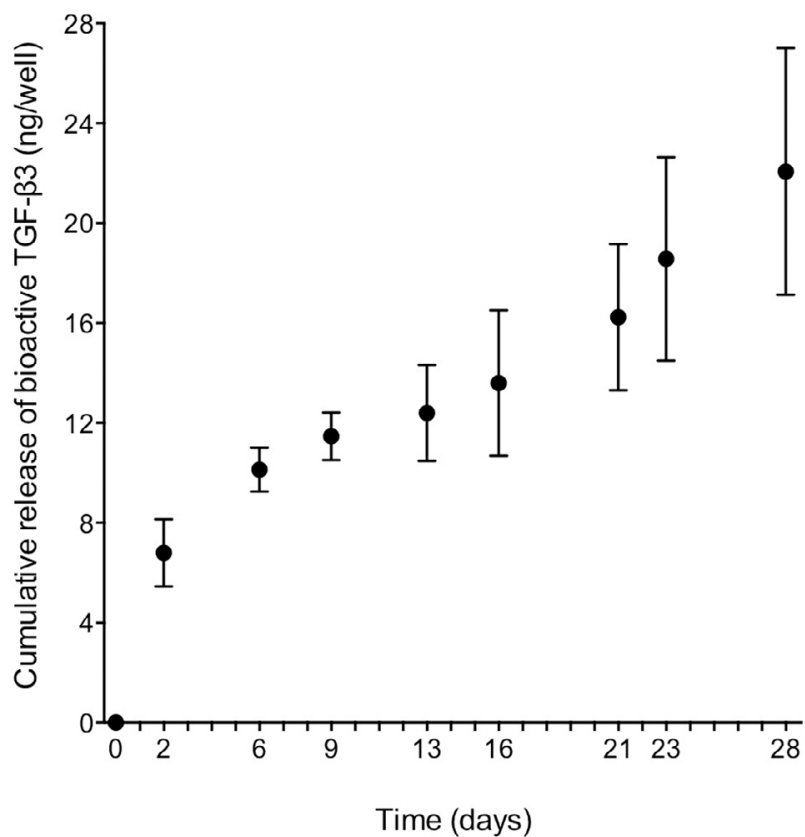

Fig. 3. In vitro release of TGF- $\beta 3$ from microspheres. Microspheres were loaded with TGF- $\beta 3$ (50 ng TGF- $\beta 3 / 100$ microspheres/well) and incubated in cell culture conditions for the indicated time. Bioactive TGF- $\beta 3$ released in the medium was quantified using a reporter gene assay. Data obtained from three independent experiments are represented as mean $\pm \mathrm{SD}$.

MSC+TGF (Fig. 5e-f). Immunohistochemistry analysis showed that there was a greater accumulation of aggrecan and type II collagen in $\mathrm{MSC}+\mathrm{mS} / \mathrm{TGF}$ and $\mathrm{MSC}+\mathrm{TGF}$ as compared to $\mathrm{MSC}+\mathrm{mS}$, confirming that chondrogenic differentiation required the presence of TGF- $\beta 3$ (Fig. 6a). Labelling of type II collagen was particularly intense in areas where cells were surrounded by lacunae, which is a known histological characteristic of chondrocytes. Of note, staining for aggrecan and type II collagen was detected in cellularised zones but also in the residual type I collagen 
a

$2 \mathrm{~h}$

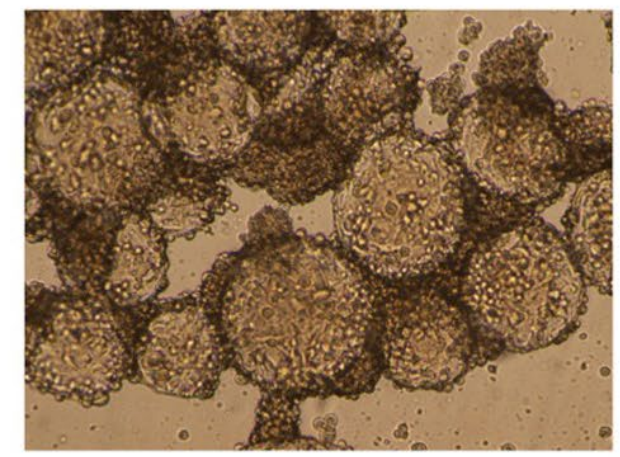

Day 2

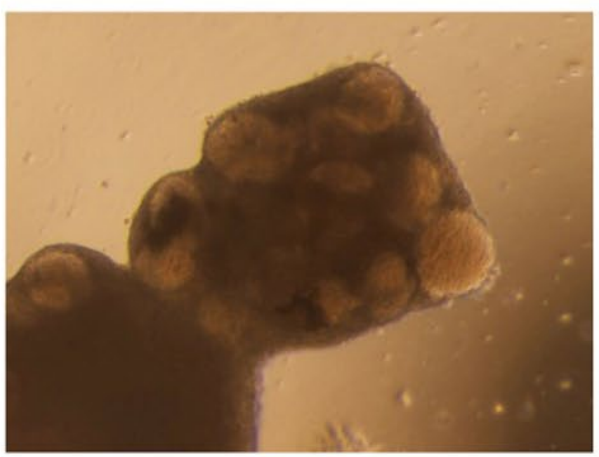

Day 21

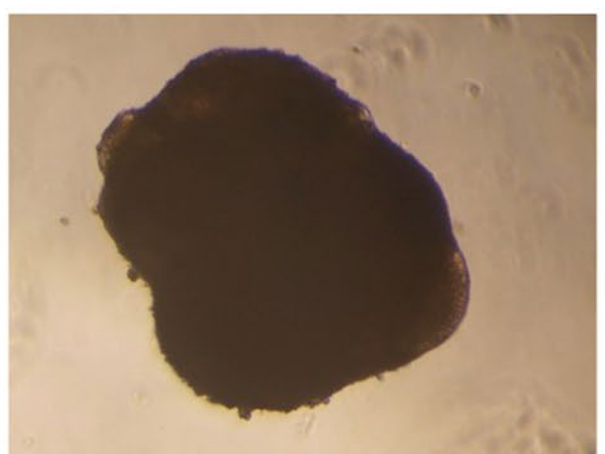

MSC+TGF

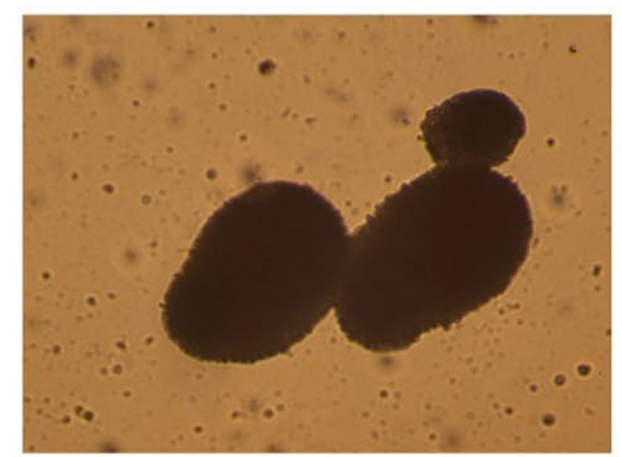

$\mathrm{MSC}+\mathrm{mS}$
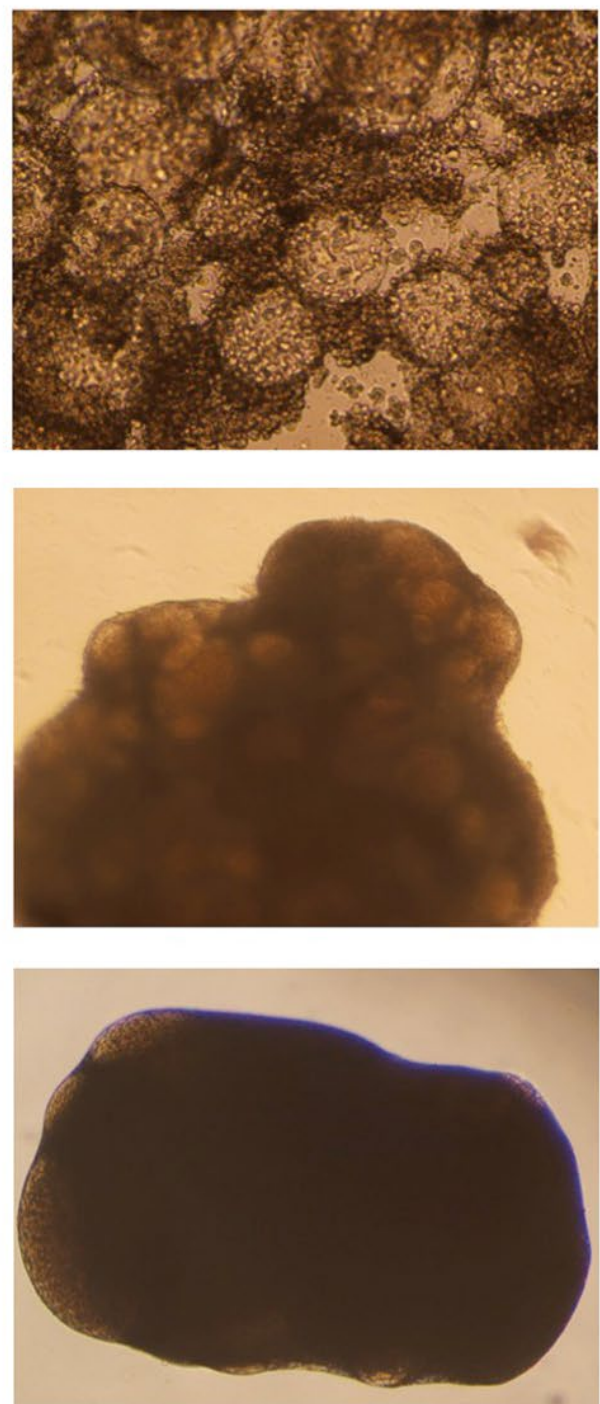

$\mathrm{mS} / \mathrm{TGF}$

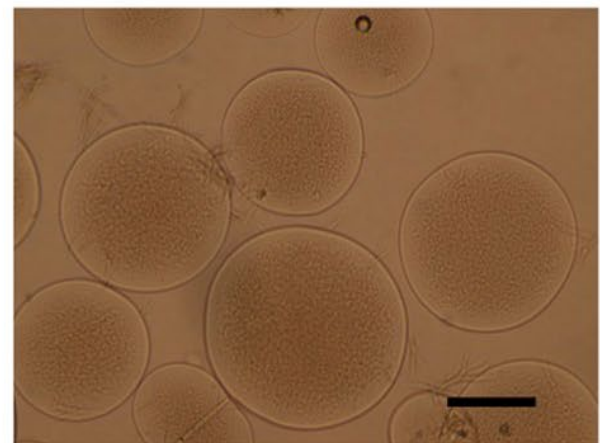

Fig. 4. Adhesion of MSC on microspheres in vitro. (a) Cells cultured with TGF- $\beta 3$-loaded microspheres (MSC $+\mathrm{mS} /$ $\mathrm{TGF}$ ) or unloaded microspheres $(\mathrm{MSC}+\mathrm{mS})$ in incomplete chondrogenic medium. (b) Cells cultured without microspheres and regularly supplied with TGF- $\beta 3$ (MSC+TGF), and TGF- $\beta 3$-loaded microspheres incubated in the absence of MSC (mS/TGF). Bar $=200 \mu \mathrm{m}$. 
a

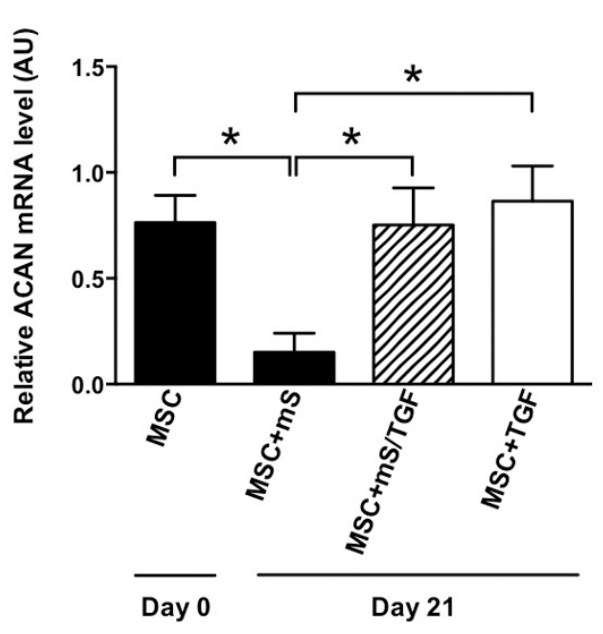

C

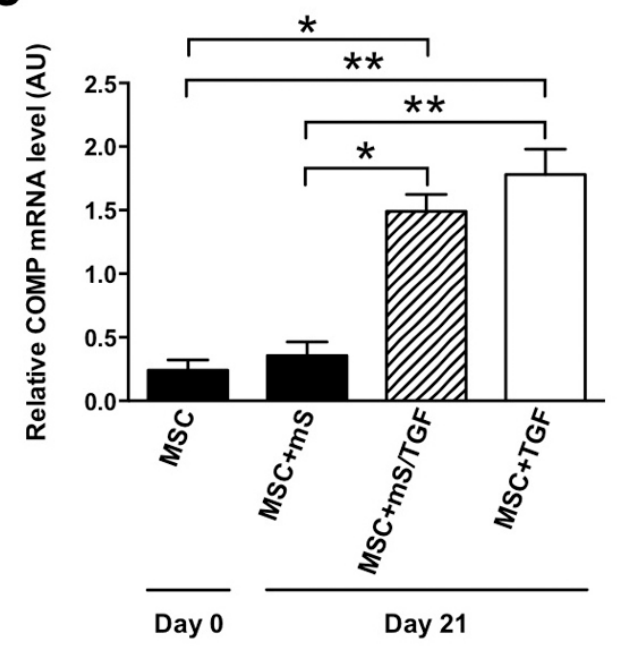

e

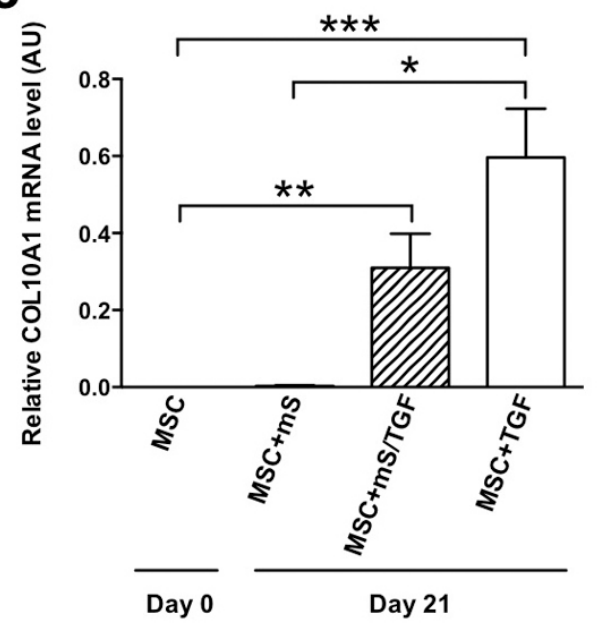

b

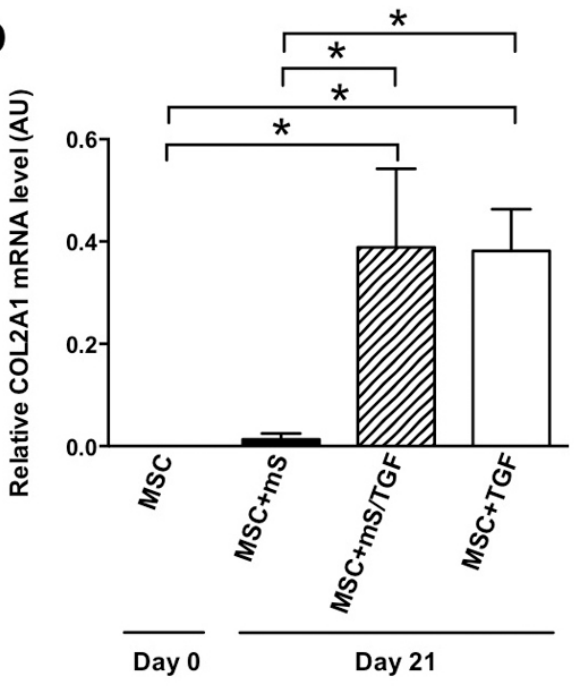

d

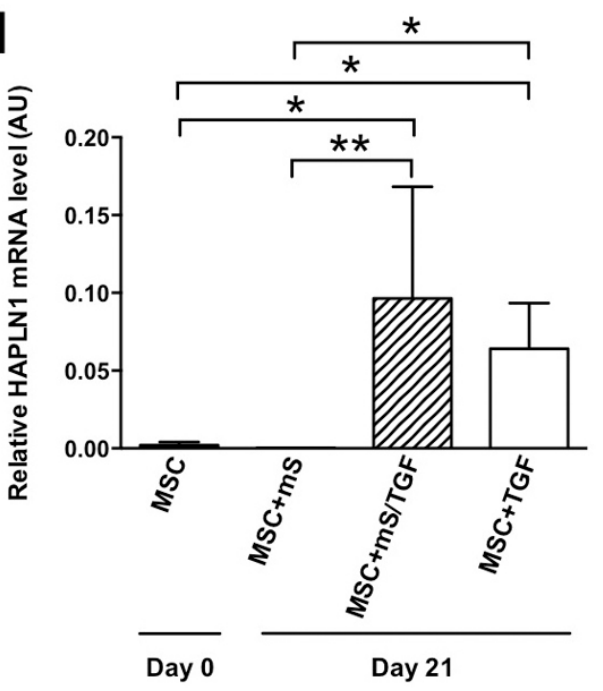

f

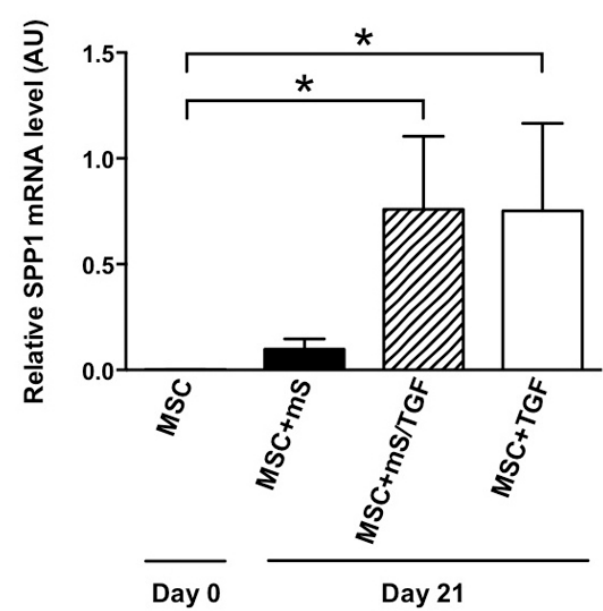

Fig. 5. Expression of chondrogenic markers in MSC cultured with TGF- $\beta 3$-loaded microspheres. Cells were mixed with unloaded (MSC $+\mathrm{mS})$ or TGF- $\beta 3$-loaded microspheres $(\mathrm{MSC}+\mathrm{mS} / \mathrm{TGF})$ and cultured for $21 \mathrm{~d}$ in the absence of TGF- $\beta 3$. Control conditions included undifferentiated MSC (day 0 ) and MSC cultured in the presence of TGF- $\beta 3$ (MSC+TGF). Relative mRNA levels of aggrecan (ACAN), variant 2 of type II collagen (COL2A1), cartilage oligomeric matrix protein (COMP), hyaluronan and proteoglycan link protein 1 (HAPLN1), type X collagen (COL10A1) and osteopontin (SPP1) were measured by RT-qPCR. The relative amount of a given mRNA was calculated by the $\Delta \Delta \mathrm{Ct}$ method and expressed in arbitrary units (AU). Data of 4 to 7 independent experiments are represented as mean $\pm \mathrm{SD}$. $* p<0.05, * * p<0.01, * * * p<0.001$. 
a

Aggrecan

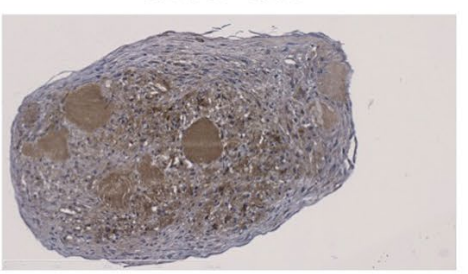

Type II collagen

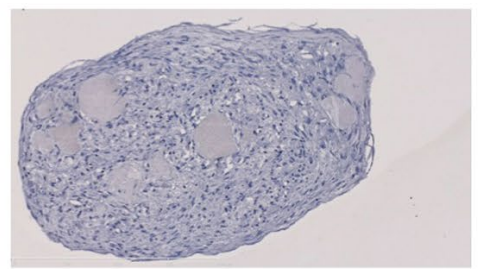

Type $X$ collagen
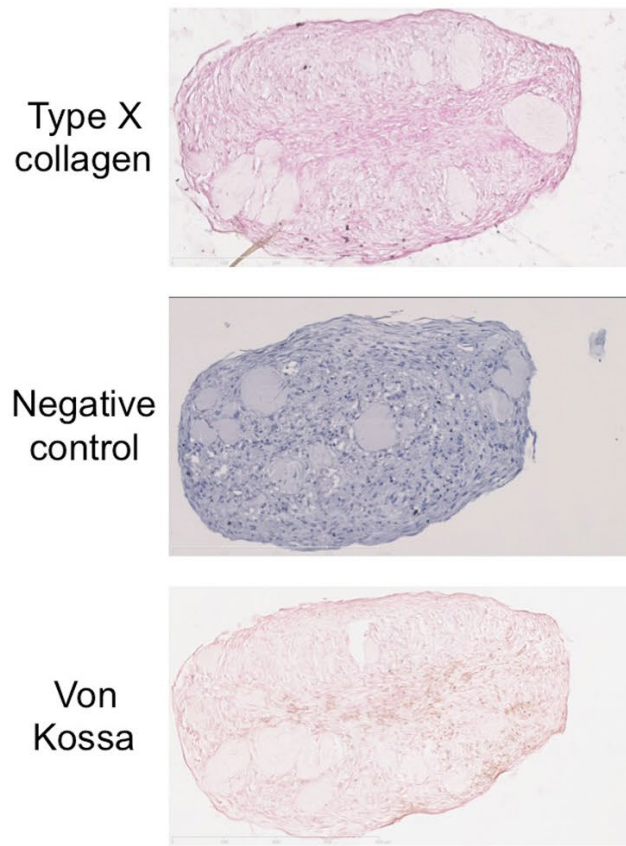

b

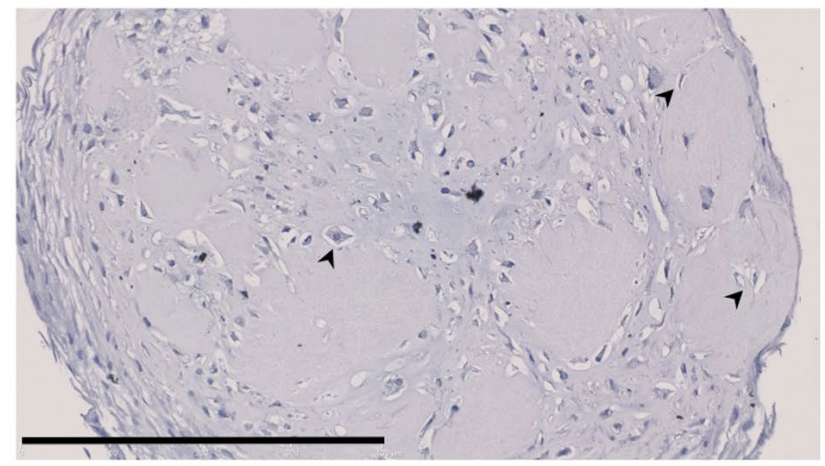

$\mathrm{MSC}+\mathrm{mS} / \mathrm{TGF}$
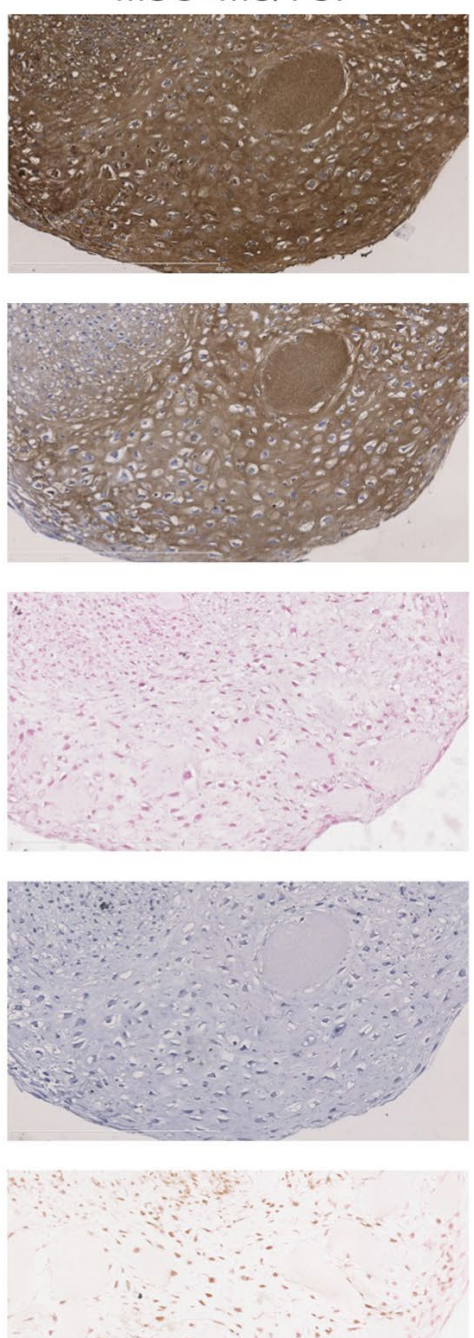

C

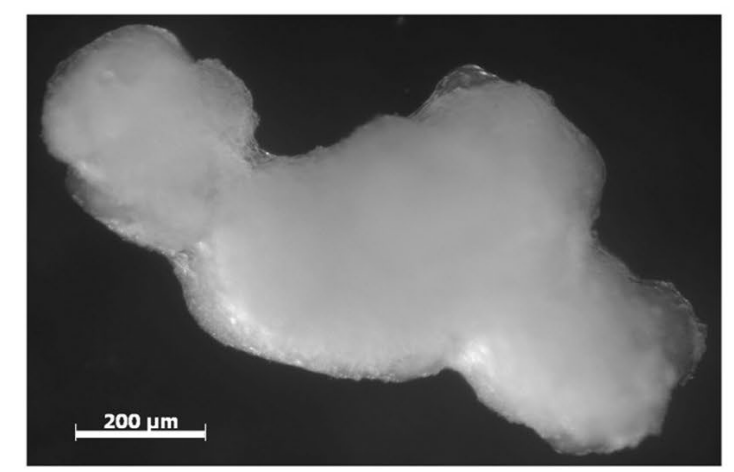

Fig. 6. Accumulation of aggrecan, type II collagen and chondrocytes in aggregates of MSC cultured with TGF- $\beta 3$ loaded microspheres. Cells were mixed with unloaded $(\mathrm{MSC}+\mathrm{mS})$ or TGF- $\beta 3$-loaded microspheres $(\mathrm{MSC}+\mathrm{mS} / \mathrm{TGF})$ and cultured for 21 or $28 \mathrm{~d}$ in the absence of TGF- $\beta 3$. Control condition corresponded to MSC cultured with regularly added TGF- $\beta 3$ (MSC+TGF). (a) Serial sections of representative aggregates obtained at day 21 were analysed by immunohistochemistry using antibodies to aggrecan, type II collagen and type X collagen, as indicated. These were also analysed for the presence of calcium deposits by von Kossa staining. Bar $=400 \mu \mathrm{m}$. (b) An aggregate of $\mathrm{MSC}+\mathrm{mS} / \mathrm{TGF}$ cultured for $28 \mathrm{~d}$ was sectioned and stained with haematoxylin. Arrowheads show chondrocyte-like cells found deep into the remnants of microspheres. Bar $=400 \mu \mathrm{m}$. (c) Stereomicroscope observation of a MSC $+\mathrm{mS} /$ TGF aggregate cultured for $28 \mathrm{~d}$. Bar $=200 \mu \mathrm{m}$. 
a

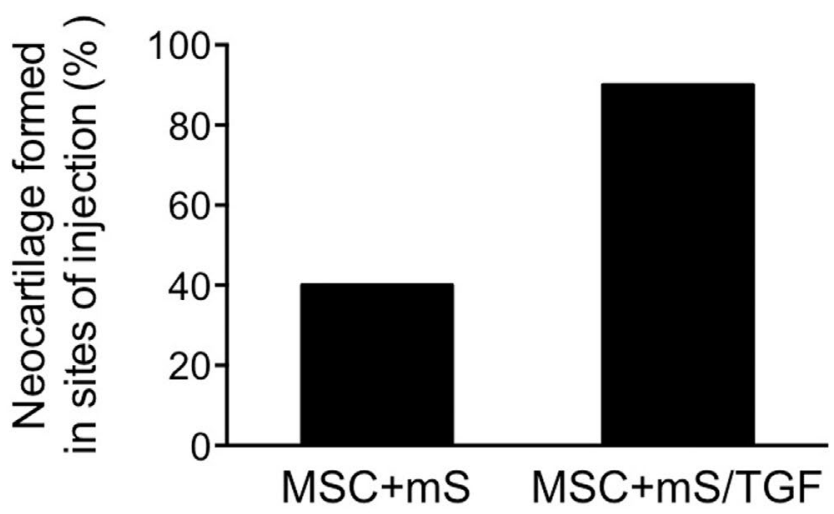

b

Fig. 7. Neocartilage formation after subcutaneous injection of MSC combined with microspheres into SCID mice. Cells were mixed with unloaded $(\mathrm{MSC}+\mathrm{mS})$ or TGF- $\beta 3$-loaded microspheres $(\mathrm{MSC}+\mathrm{mS} / \mathrm{TGF})$, and subcutaneously injected in SCID mice. Twenty one days later, neotissues forming solid lumps, which corresponded to putative neocartilage, were collected. (a) Rate of neotissue formation at injection sites for both conditions $(n=10)$. (b) Histological sections of neotissues stained with Alcian blue. Bar $=400 \mu \mathrm{m}$.

$\mathrm{MSC}+\mathrm{mS}$

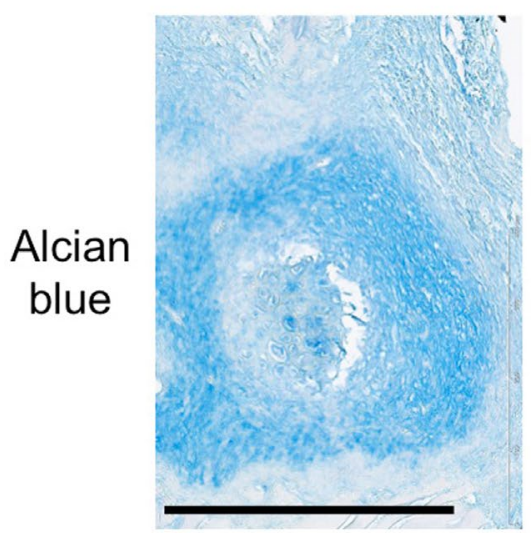

$\mathrm{MSC}+\mathrm{mS} / \mathrm{TGF}$

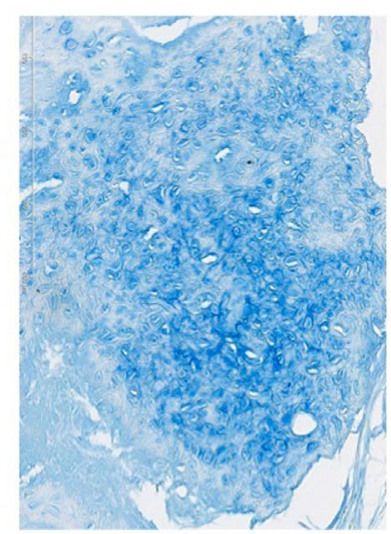

microspheres. This latter observation can be explained by the previously reported interaction of the aggrecan core protein with both type I and type II collagen (Hedlund et al., 1999). Type X collagen was undetectable in any conditions (Fig. 6a), even though its mRNA was induced in the presence of TGF- $\beta 3$ (Fig. 5e). Moreover, in all analysed samples, the extracellular matrix was not mineralised as indicated by the absence of von Kossa staining (Fig. 6a). The procedures used to immunodetect type $\mathrm{X}$ collagen and reveal calcium deposits were reliable since positive labellings were obtained on murine growth plate cartilage and bone, respectively (data not shown), as well as on subcutaneous implants of MSC $+\mathrm{mS} / \mathrm{TGF}$ (Figs. $8 \mathrm{a}$ and $\mathrm{b}$ ). Similar results were obtained after $28 \mathrm{~d}$ of culture (data not shown). Examination of histological sections at this stage indicated that although cells were preferentially localised around the microspheres, they were sometimes found deep into the remnants of TGF- $\beta 3$-loaded microspheres (Fig. 6b). The tissue formed by $\mathrm{MSC}+\mathrm{mS} / \mathrm{TGF}$ samples at day 28 had a white-opaque aspect similar to that of native cartilage when observed by stereomicroscopy (Fig. 6c).

\section{In vivo neocartilage formation}

We next examined whether TGF- $\beta 3$-loaded microspheres were suitable as active carriers for chondrogenic differentiation of MSC in vivo. To this purpose, these microspheres were mixed with $\mathrm{MSC}$ and injected subcutaneously into SCID mice. Unloaded microspheres seeded with MSC were used as controls. After $21 \mathrm{~d}$, a solid lump under the skin appeared at some implantation sites. This indicated that neocartilage had potentially formed at these sites. All corresponding neotissues were hence collected and processed for histological and immunohistochemical analyses. Macroscopically, all neotissues had after dissection a white-opaque aspect resembling that of native cartilage (data not shown). Importantly, a solid lump has formed in $90 \%$ of the sites implanted with $\mathrm{MSC}+\mathrm{mS} / \mathrm{TGF}$, but in only $40 \%$ of the sites implanted with $\mathrm{MSC}+\mathrm{mS}(p=0.0286$, Fisher's exact test) (Fig. 7a). On histological sections, samples collected from both conditions displayed features of chondrogenic differentiation. A differentiated tissue containing chondrocyte-like cells appeared in central regions that stained with Alcian blue, indicating the presence of glycosaminoglycans (Fig. 7b). Aggrecan was broadly expressed in the neotissues, while a strong type II collagen staining was detected only at discrete sites in the differentiated part of the tissues (Fig. 8a). Implants of $\mathrm{MSC}+\mathrm{mS} / \mathrm{TGF}$ expressed type $\mathrm{X}$ collagen and were mineralised as opposed to those of MSC $+\mathrm{mS}$ (Figs. 8a and b). Calcium deposits visualised by von Kossa staining accumulated in the matrix surrounding chondrocytes (Fig. $8 \mathrm{~b}$, top right panel and enlargement). Implants of $\mathrm{MSC}+\mathrm{mS} /$ TGF were densely vascularised as shown by the presence 
a

Fig. 8. Chondrogenic differentiation, calcification and vascularisation, after subcutaneous injection of MSC combined with microspheres into SCID mice. Cells were mixed with unloaded $(\mathrm{MSC}+\mathrm{mS})$ or TGF$\beta 3$-loaded microspheres ( $\mathrm{M} \mathrm{S} \mathrm{C}+\mathrm{m} \mathrm{S} / \mathrm{T} \mathrm{GF}$ ), and subcutaneously injected in SCID mice. Twenty one days later, neotissues forming solid lumps were collected. (a) Immunohistochemistry a n a l y s e s of serial sections of representative neotissues with antibodies to aggrecan, type II collagen, type $\mathrm{X}$ collagen and human mitochondria, a s indicated. Bar $=400 \mu \mathrm{m}$. (b) Mineralisation of the matrix assessed by von Kossa staining. Bar $=400 \mu \mathrm{m}$. An enlargement is shown to better distinguish eosin coloured red blood cell (arrows). Bar $=100 \mu \mathrm{m}$. In the bottom panels, approximately the same region in a serial section was stained with haematoxylin and eosin. Nuclei of endothelial cells (arrowheads). Bar $=100 \mu \mathrm{m}$.

b

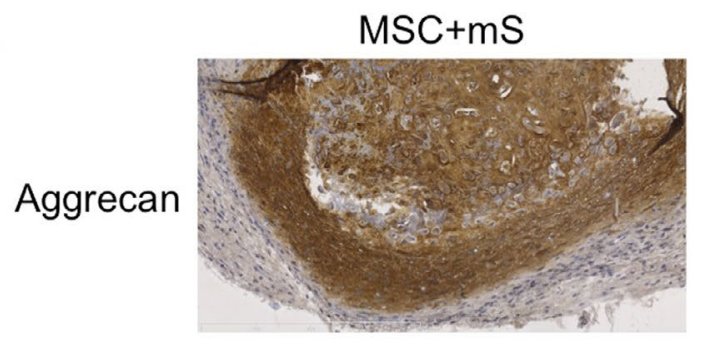

Type II collagen

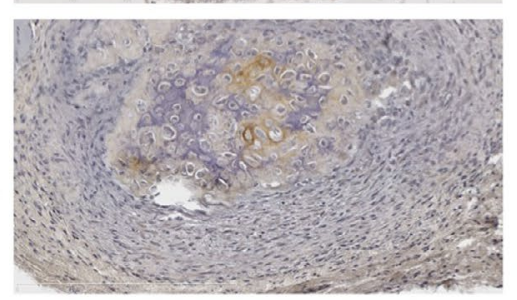

\section{Type $X$} collagen

\section{Human mitochondria}
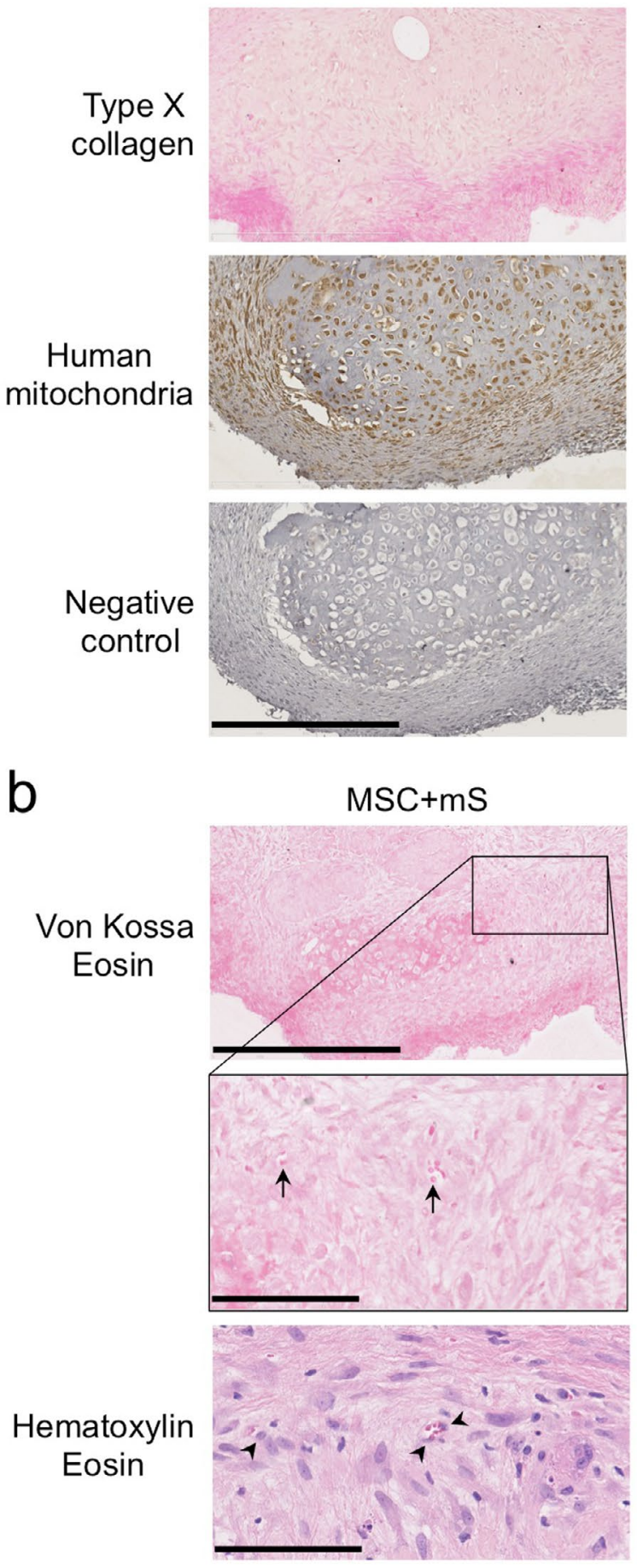
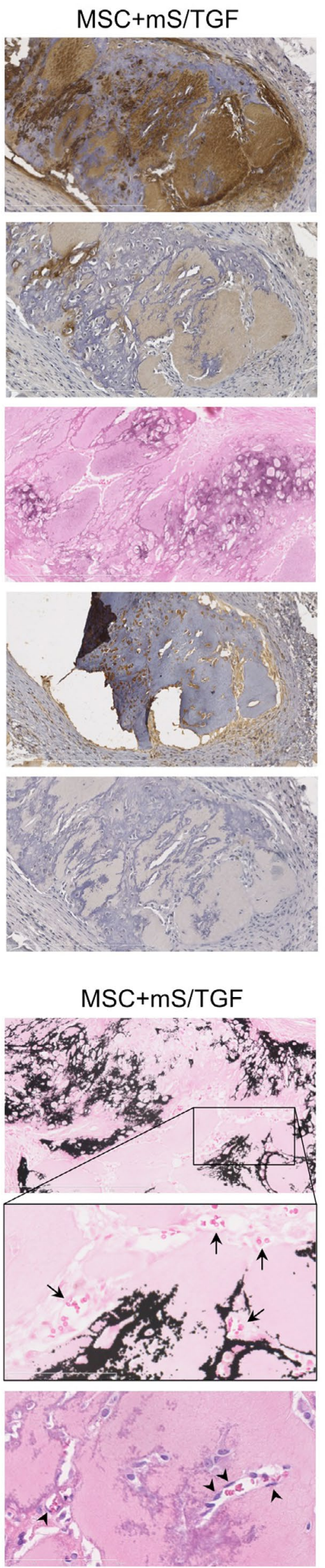
of red blood cells having the typical aspect of biconcave disks intensely coloured by eosin (Fig. 8b, right panels). These erythrocytes were confined in the unstained lumen of capillaries formed by endothelial cells whose nuclei were clearly stained by haematoxylin (Fig. 8b, bottom right panel). Vascularisation was apparently less developed in implants of $\mathrm{MSC}+\mathrm{mS}$, particularly in the region containing the differentiated cells (Fig 8b, left panels). The human origin of the neocartilage was demonstrated using an antibody directed specifically against human mitochondria. With this antibody, cytoplasmic organelles were stained in chondrocyte-like cells but also in cells located in the periphery of the neotissue, indicating that a proportion of the implanted human cells had migrated into the surrounding murine tissue (Fig. 8a).

\section{Discussion}

The development of injectable biomaterials that can be used as active microcarriers for chondrogenic differentiation of MSC is a field of active research. In the present work, type I collagen was processed into microspheres of $\sim 300 \mu \mathrm{m}$ diameter because this formulation presented several advantages, among which are injectability, ease of handling, collecting and quantifying. The microspheres could be kept intact for at least 3 months at room temperature in sterile conditions, allowing their use off-the-shelf at any time during this period. Unlike most collagen- or gelatinbased microspheres previously studied for biomedical applications, the particle formation method described here does not require chemical crosslinking to strengthen and stabilise their structure (Han et al., 2010; Rossler et al., 1995; Solorio et al., 2012). The relatively high collagen density that we used ensures enough cohesion through physical gelation to avoid the use of potentially toxic crosslinking agents that can be ultimately released in vivo after implantation. In our process, acid-solubilised collagen molecules aggregate during the neutralisation step into fibrils harbouring the same cross-striated patterns as native collagen. The resulting meshwork stabilises the structure and shape of the microspheres. When these microspheres were loaded with TGF- $\beta 3$, they progressively released this differentiation factor over four weeks and did not produce the initial burst usually seen with gelatin-based microspheres (Han et al., 2010; Solorio et al., 2012). A specific interaction has been reported between TGF- $\beta 1$ and type I collagen (Shibuya et al., 2006). The almost zero-order release kinetics observed here suggests that such binding also exists between TGF- $\beta 3$ and type I collagen. This release profile should limit side effects due to fast and excessive release of TGF- $\beta 3$ in vivo. Indeed, besides its potent chondrogenic effect, TGF- $\beta 3$, when overexpressed, has been shown to induce inflammation, synovial hyperplasia, synovitis and osteophyte formation in the murine knee joint (Bakker et al., 2001; van Beuningen et al., 1994).

The binding capacity of gelatin towards integrins has been shown to be lower than that of native triplehelical collagen, and can be further affected by chemical crosslinking (Grover et al., 2012). Because binding through integrins promotes cell adhesion (Durr et al., 1993; Enomoto et al., 1993) and chondrogenic differentiation (Segat et al., 2002), we expected that our microspheres would exhibit a strong ability to support cell adhesion and differentiation. Indeed, we found that most cells adhered to the microspheres in two hours and were subsequently able to differentiate into chondrocytes. Moreover, the seeding condition that we have chosen triggered rapid covering of the whole available surface and formation of large 3D aggregates of condensed cells, a situation known to facilitate differentiation into the chondrocytic lineage (Mackay et al., 1998; Yoo et al., 1998). Nevertheless, loading the microspheres with TGF- $\beta 3$ was crucial to obtain chondrogenic differentiation in vitro. Similarly, the capacity of MSC to form a cartilage-like tissue after subcutaneous implantation was consistently observed with TGF- $\beta 3$-loaded microspheres, while such tissue was less frequently obtained after injection of MSC combined to unloaded microspheres. We hypothesise that in this latter instance, unknown diffusible factors from surrounding murine tissues may have induced chondrogenic differentiation. In this regard, the dermis and epidermis are known sites of TGF- $\beta$ expression (Levine $e t$ al., 1993).

For articular cartilage regeneration, the hypertrophic differentiation of chondrocytes is unwanted because it alters the biomechanical properties of the matrix and prepares the tissue for neovascularisation and subsequent ossification. Withdrawal of TGF- $\beta 3$ in the course of in vitro chondrogenesis was shown to facilitate further differentiation of MSC towards the hypertrophic state (Mackay et al., 1998). Thus, continuous release of TGF- $\beta 3$ by the microspheres should limit this terminal differentiation step. However, the present experiments showed that hypertrophic markers were still expressed, in particular type X collagen which was found to accumulate in the neotissues formed subcutaneously after injection of MSC combined with TGF-loaded microspheres. Furthermore, the neocartilage formed after subcutaneous implantation exhibited a patchy accumulation of collagen type II and was calcified, as opposed to that formed in vitro. Formation of a calcified neocartilage has also been reported by others following subcutaneous implantation of hyaluronic acid hydrogel disks containing MSC and alginate microspheres delivering TGF- $\beta 3$ (Bian et al., 2011). These data suggest that the vascularised subcutaneous ectopic environment is not adequate for stabilising the mature phenotype of cartilage, and is promoting hypertrophy and mineralisation in the presence of a TGF- $\beta 3$ releasing scaffold. In the present study, these unwanted effects were associated with neovascularisation of the implants as shown by the presence of numerous capillaries containing red blood cells and distributed throughout the neotissue. Although we did not quantify vascularisation, this was apparently less dense within the implants obtained with unloaded-microspheres. We speculate that TGF- $\beta 3$ released by the scaffold, and probably vascular endothelial growth factor produced by hypertrophic chondrocytes (Gerber et al., 1999), were responsible for enhanced angiogenesis, which in turn is known to promote osteogenesis. In agreement with this hypothesis, TGF- $\beta$ was shown to induce tubulogenesis in 
collagen gels (Sankar et al., 1996) and play an active role in several aspects of vascular development (for review see Pepper, 1997).

Importantly, it is expected that after orthotopic implantation into a cartilage defect, hypertrophic differentiation within the implants is restricted to the deep layer, adjacent to subchondral bone, thus respecting the zonal organisation of native cartilage (Steck et al., 2009). Indeed, cycles of mechanical loading and a hypoxic/ avascular environment, both of which occur naturally in articular cartilage, have been shown to increase chondrocyte anabolic activity and reduce hypertrophy (for review see Ramage et al., 2009; Studer et al., 2012). For this reason, as well as to reduce the time during which the cells are cultured with the biomaterial ex vivo, we developed an approach where MSC are injected soon after combination with the TGF- $\beta 3$-loaded microspheres so that differentiation occurs in vivo. The alternative strategy consisting in incorporating the cells into microspheres during their preparation and pre-differentiating them in vitro for three weeks before implantation was envisaged by others (Hui et al., 2008), but would be less straightforward in terms of safety, costs and logistical organisation of the surgical procedure. We are continuing investigations aimed at inhibiting hypertrophic differentiation by optimising the local environment of cells on the microspheres. In the present study, we loaded the beads with an amount of TGF- $\beta 3$ equivalent to that used cumulatively during chondrogenic differentiation of MSC by the usual micromass culture. Given that TGF- $\beta 3$ was associated with and released from these type I collagen microspheres in the immediate vicinity of the cells, its local concentration probably reached higher values than when simply added in the culture medium. In addition, if TGF- $\beta 3$ interacts with type I collagen, as has been shown for TGF- $\beta 1$ (Shibuya et al., 2006), it would then be similarly protected from proteolysis and would have an enhanced half-life. Because high levels of TGF- $\beta$ in synovial fluid and subchondral bone have been associated with the formation of osteophytes and marrow osteoid islets, respectively (Bakker et al., 2001; van Beuningen et al., 1994; Zhen et al., 2013), one strategy to gain control over MSC differentiation and limit hypertrophy and mineralisation will be to reduce drastically the level of TGF- $\beta 3$ loaded into the microspheres. We hypothesise that the lowest amount of TGF- $\beta 3$ required to trigger chondrogenesis may also induce minimal hypertrophy. We also contemplate a complementary strategy that consists of delivering in a delayed fashion a hypertrophy inhibitor, such as parathyroid hormone-related protein (PTHrP), by chemically grafting the protein to the collagen scaffold with stimuli-responsive moieties. Indeed, previous studies have shown that early treatment of MSC with PTHrP suppressed TGF- $\beta$-driven chondrogenic differentiation (Weiss et al., 2010), and that quick release of this factor by a scaffold did not prevent extensive mineralisation of subcutaneous implants (Bian et al., 2011).

\section{Conclusions}

Here, we demonstrated the feasibility of a novel potential cartilage engineering approach based on MSC and selfcross-linked collagen microspheres carrying TGF- $\beta 3$. In the present proof of principle study, we were able to successfully induce chondrogenic differentiation in vitro and the formation of a tissue resembling cartilage in vivo. However, induction of hypertrophy and calcification is an issue that needs to be addressed in future studies. The interest of these collagen microspheres resides in the versatility of the simple impregnation method used for loading the differentiation factor, ease of handling, and potentially rapid transfer to the clinic thanks to the nature and structure of this injectable scaffold which does not require differentiation of MSC prior to implantation.

\section{Acknowledgements}

We thank Silvine Benth, Marisa Teigell and Heiani Touaitahuata for technical assistance. This study was supported by the Inserm Institute, the University of Montpellier I and funding from the CNRS (Programme Interdisciplinaire "Longévité \& Vieillissement»), the program "Bonus de l'Université de Montpellier I de Soutien à la Recherche" and the Agence de la Biomédecine. We thank the "Réseau des Animaleries de Montpellier" animal facility, the "Réseau d'Histologie Expérimentale de Montpellier" histology facility for processing our animal tissues, and the "Montpellier RIO Imaging" platform. We also thank the Agence Nationale pour la Recherche for support of the national infrastructure "ECELLFRANCE: Development of a national adult mesenchymal stem cell based therapy platform" (ANR-11-INSB-005). We wish to confirm that there are no known conflicts of interest associated with this publication and there has been no significant financial support for this work that could have influenced its outcome.

\section{References}

Bakker AC, van de Loo FA, van Beuningen HM, Sime P, van Lent PL, van der Kraan PM, Richards CD, van den Berg WB (2001) Overexpression of active TGF-beta-1 in the murine knee joint: evidence for synovial-layerdependent chondro-osteophyte formation. Osteoarthritis Cartilage 9: 128-136.

Balakrishnan B, Banerjee R (2011) Biopolymer-based hydrogels for cartilage tissue engineering. Chem Rev 111: 4453-4474.

Barry F, Boynton RE, Liu B, Murphy JM (2001) Chondrogenic differentiation of mesenchymal stem cells from bone marrow: differentiation-dependent gene expression of matrix components. Exp Cell Res 268: 189200.

Bell E, Ivarsson B, Merrill C (1979) Production of a tissue-like structure by contraction of collagen lattices by human fibroblasts of different proliferative potential in vitro. Proc Natl Acad Sci USA 76: 1274-1278. 
Bergman I, Loxley R (1963) Two improved and simplified methods for the spectrophotometric determination of hydroxyproline. Anal Chem 35: 1961 1965.

Bian L, Zhai DY, Tous E, Rai R, Mauck RL, Burdick JA (2011) Enhanced MSC chondrogenesis following delivery of TGF-beta3 from alginate microspheres within hyaluronic acid hydrogels in vitro and in vivo. Biomaterials 32: 6425-6434.

Caplan AI (2007) Adult mesenchymal stem cells for tissue engineering versus regenerative medicine. J Cell Physiol 213: 341-347.

Clausell-Tormos J, Lieber D, Baret JC, El-Harrak A, Miller OJ, Frenz L, Blouwolff J, Humphry KJ, Koster S, Duan H, Holtze C, Weitz DA, Griffiths AD, Merten CA (2008) Droplet-based microfluidic platforms for the encapsulation and screening of mammalian cells and multicellular organisms. Chem Biol 15: 427-437.

Crawford DC, DeBerardino TM, Williams RJ (2012) NeoCart, an autologous cartilage tissue implant, compared with microfracture for treatment of distal femoral cartilage lesions: An FDA phase-II prospective, randomized clinical trial after two years. J Bone Joint Surg Am 94: 979-989.

Djouad F, Bony C, Haupl T, Uze G, Lahlou N, Louis-Plence P, Apparailly F, Canovas F, Reme T, Sany J, Jorgensen C, Noel D (2005) Transcriptional profiles discriminate bone marrow-derived and synovium-derived mesenchymal stem cells. Arthritis Res Ther 7: R13041315.

Durr J, Goodman S, Potocnik A, von der Mark H, von der Mark K (1993) Localization of beta 1-integrins in human cartilage and their role in chondrocyte adhesion to collagen and fibronectin. Exp Cell Res 207: 235-244.

Engler A, Bacakova L, Newman C, Hategan A, Griffin M, Discher D (2004) Substrate compliance versus ligand density in cell on gel responses. Biophys J 86: 617-628.

Engler AJ, Sen S, Sweeney HL, Discher DE (2006) Matrix elasticity directs stem cell lineage specification. Cell 126: 677-689.

Enomoto M, Leboy PS, Menko AS, Boettiger D (1993) Beta 1 integrins mediate chondrocyte interaction with type I collagen, type II collagen, and fibronectin. Exp Cell Res 205: 276-285.

Gerber HP, Vu TH, Ryan AM, Kowalski J, Werb Z, Ferrara N (1999) VEGF couples hypertrophic cartilage remodeling, ossification and angiogenesis during endochondral bone formation. Nat Med 5: 623-628.

Gobeaux F, Mosser G, Anglo A, Panine P, Davidson P, Giraud-Guille MM, Belamie E (2008) Fibrillogenesis in dense collagen solutions: a physicochemical study. J Mol Biol 376: 1509-1522.

Grover CN, Gwynne JH, Pugh N, Hamaia S, Farndale RW, Best SM, Cameron RE (2012) Crosslinking and composition influence the surface properties, mechanical stiffness and cell reactivity of collagen-based films. Acta Biomater 8: 3080-3090.

Hamdoune F, El Moujahid C, Rodehuser L, Gerardin C, Henry B, Stebe MJ, Amos J, Marraha M, Asskali A, Selve C (2000) Amphiphilic and cation-complexing compounds based on peptidoamines. New J Chem 24: 1037-1042.
Han Y, Wei Y, Wang S, Song Y (2010) Cartilage regeneration using adipose-derived stem cells and the controlled-released hybrid microspheres. Joint Bone Spine 77: 27-31.

Hedlund H, Hedbom E, Heinegard D, MengarelliWidholm S, Reinholt FP, Svensson O (1999) Association of the aggrecan keratan sulfate-rich region with collagen in bovine articular cartilage. J Biol Chem 274: 5777-5781.

Holtze C, Rowat AC, Agresti JJ, Hutchison JB, Angile FE, Schmitz CH, Koster S, Duan H, Humphry KJ, Scanga RA, Johnson JS, Pisignano D, Weitz DA (2008) Biocompatible surfactants for water-in-fluorocarbon emulsions. Lab Chip 8: 1632-1639.

Hui TY, Cheung KM, Cheung WL, Chan D, Chan BP (2008) In vitro chondrogenic differentiation of human mesenchymal stem cells in collagen microspheres: influence of cell seeding density and collagen concentration. Biomaterials 29: 3201-3212.

Johnstone B, Hering TM, Caplan AI, Goldberg VM, Yoo JU (1998) In vitro chondrogenesis of bone marrowderived mesenchymal progenitor cells. Exp Cell Res 238: 265-272.

Levine JH, Moses HL, Gold LI, Nanney LB (1993) Spatial and temporal patterns of immunoreactive transforming growth factor beta 1, beta 2 , and beta 3 during excisional wound repair. Am J Pathol 143: 368-380.

Li CH, Chik TK, Ngan AH, Chan SC, Shum DK, Chan BP (2011) Correlation between compositional and mechanical properties of human mesenchymal stem cellcollagen microspheres during chondrogenic differentiation. Tissue Eng Part A 17: 777-788.

Livak KJ, Schmittgen TD (2001) Analysis of relative gene expression data using real-time quantitative PCR and the 2(-Delta Delta C(T)) method. Methods 25: 402-408.

Lutolf MP, Gilbert PM, Blau HM (2009) Designing materials to direct stem-cell fate. Nature 462: 433-441.

Mackay AM, Beck SC, Murphy JM, Barry FP, Chichester CO, Pittenger MF (1998) Chondrogenic differentiation of cultured human mesenchymal stem cells from marrow. Tissue Eng 4: 415-428.

Maumus M, Guerit D, Toupet K, Jorgensen C, Noel D (2011) Mesenchymal stem cell-based therapies in regenerative medicine: applications in rheumatology. Stem Cell Res Ther 2: 14.

Mwale F, Stachura D, Roughley P, Antoniou J (2006) Limitations of using aggrecan and type $\mathrm{X}$ collagen as markers of chondrogenesis in mesenchymal stem cell differentiation. J Orthop Res 24: 1791-1798.

Nakamura N, Miyama T, Engebretsen L, Yoshikawa H, Shino K (2009) Cell-based therapy in articular cartilage lesions of the knee. Arthroscopy 25: 531-552.

Ode A, Duda GN, Glaeser JD, Matziolis G, Frauenschuh S, Perka C, Wilson CJ, Kasper G (2010) Toward biomimetic materials in bone regeneration: functional behavior of mesenchymal stem cells on a broad spectrum of extracellular matrix components. J Biomed Mater Res A 95: 1114-1124.

Pacak CA, Powers JM, Cowan DB (2011) Ultrarapid purification of collagen type I for tissue engineering applications. Tissue Eng Part C Methods 17: 879-885. 
Park JS, Chu JS, Tsou AD, Diop R, Tang Z, Wang A, Li $S$ (2011) The effect of matrix stiffness on the differentiation of mesenchymal stem cells in response to TGF-beta. Biomaterials 32: 3921-3930.

Pepper MS (1997) Transforming growth factor-beta: vasculogenesis, angiogenesis, and vessel wall integrity. Cytokine Growth Factor Rev 8: 21-43.

Ramage L, Nuki G, Salter DM (2009) Signalling cascades in mechanotransduction: cell-matrix interactions and mechanical loading. Scand J Med Sci Sports 19: $457-$ 469.

Rossler B, Kreuter J, Scherer D (1995) Collagen microparticles: preparation and properties. J Microencapsul 12: 49-57.

Rozen S, Skaletsky HJ (2000) Primer3 on the WWW for general users and for biologist programmers. In: Krawetz S and Misener S (eds) Bioinformatics Methods and Protocols: Methods in Molecular Biology. Humana Press, Totowa, pp 365-386.

Sankar S, Mahooti-Brooks N, Bensen L, McCarthy TL, Centrella M, Madri JA (1996) Modulation of transforming growth factor beta receptor levels on microvascular endothelial cells during in vitro angiogenesis. J Clin Invest 97: 1436-1446.

Segat D, Comai R, Di Marco E, Strangio A, Cancedda R, Franzi AT, Tacchetti C (2002) Integrins alpha(6A) beta 1 and alpha(6B)beta 1 promote different stages of chondrogenic cell differentiation. J Biol Chem 277: $31612-$ 31622.

Shibuya H, Okamoto O, Fujiwara S (2006) The bioactivity of transforming growth factor-betal can be regulated via binding to dermal collagens in mink lung epithelial cells. J Dermatol Sci 41: 187-195.

Shoseyov O, Posen Y, Grynspan F (2013) Human recombinant type I collagen produced in plants. Tissue Eng Part A 19: 1527-1533.

Solorio LD, Dhami CD, Dang PN, Vieregge EL, Alsberg E (2012) Spatiotemporal regulation of chondrogenic differentiation with controlled delivery of transforming growth factor-betal from gelatin microspheres in mesenchymal stem cell aggregates. Stem Cells Transl Med 1: 632-639.

Speer DP, Chvapil M, Eskelson CD, Ulreich J (1980) Biological effects of residual glutaraldehyde in glutaraldehyde-tanned collagen biomaterials. J Biomed Mater Res 14: 753-764.

Steck E, Fischer J, Lorenz H, Gotterbarm T, Jung M, Richter W (2009) Mesenchymal stem cell differentiation in an experimental cartilage defect: restriction of hypertrophy to bone-close neocartilage. Stem Cells Dev 18: 969-978.

Studer D, Millan C, Ozturk E, Maniura-Weber K, Zenobi-Wong M (2012) Molecular and biophysical mechanisms regulating hypertrophic differentiation in chondrocytes and mesenchymal stem cells. Eur Cell Mater 24: 118-135.

Tesseur I, Zou K, Berber E, Zhang H, Wyss-Coray $\mathrm{T}$ (2006) Highly sensitive and specific bioassay for measuring bioactive TGF-beta. BMC Cell Biol 7: 15 .

van Beuningen HM, van der Kraan PM, Arntz OJ, van den Berg WB (1994) Transforming growth factor-beta 1 stimulates articular chondrocyte proteoglycan synthesis and induces osteophyte formation in the murine knee joint. Lab Invest 71: 279-290.

Vinatier C, Bouffi C, Merceron C, Gordeladze J, Brondello JM, Jorgensen C, Weiss P, Guicheux J, Noel D (2009) Cartilage tissue engineering: towards a biomaterialassisted mesenchymal stem cell therapy. Curr Stem Cell Res Ther 4: 318-329.

Weiss S, Hennig T, Bock R, Steck E, Richter W (2010) Impact of growth factors and PTHrP on early and late chondrogenic differentiation of human mesenchymal stem cells. J Cell Physiol 223: 84-93.

Wiebe D, Megerman J, L'Italien GJ, Abbott WM (1988) Glutaraldehyde release from vascular prostheses of biologic origin. Surgery 104: 26-33.

Yoo JU, Barthel TS, Nishimura K, Solchaga L, Caplan AI, Goldberg VM, Johnstone B (1998) The chondrogenic potential of human bone-marrow-derived mesenchymal progenitor cells. J Bone Joint Surg Am 80: 1745-1757.

Zhen G, Wen C, Jia X, Li Y, Crane JL, Mears SC, Askin FB, Frassica FJ, Chang W, Yao J, Carrino JA, Cosgarea A, Artemov D, Chen Q, Zhao Z, Zhou X, Riley L, Sponseller P, Wan M, Lu WW, Cao X (2013) Inhibition of TGF-beta signaling in mesenchymal stem cells of subchondral bone attenuates osteoarthritis. Nat Med 19: 704-712.

Zhu S, Edmonds WF, Hillmyer MA, Lodge TP (2005) Synthesis and self-assembly of highly incompatible polybutadiene-poly(hexafluoropropylene oxide) diblock copolymers. J Polym Sci Part B Polym Phys 43: $3685-$ 3694.

\section{Discussion with Reviewers}

Reviewer I: With respect to stabilising the hyaline cartilage phenotype for joint resurfacing applications, even if some compound, like PTHrP, is effective for preventing hypertrophy, what happens when the PTHrP within the microspheres is exhausted? Is there any evidence that the hyaline phenotype can be made stable?

Authors: We think that preventing hypertrophy might only be required at the end of the TGFbeta-induced chondrogenic differentiation process. Indeed, once differentiated into chondrocytes, the cells should be influenced by the local environment, which in the cartilage favours anabolic activity and the stabilisation of functional cartilage through chemical, biochemical and mechanical cues (for review see Ramage et al., 2009; Studer et al., 2012). Of course, this positive influence will require a good integration of the implant into the host tissue. We believe that a collagenbased scaffold, such as the one developed here, through its adhesive properties should facilitate integration of the implant. Current cartilage repair strategies have failed to generate long lasting hyaline cartilage replacement tissue (Steinert et al., 2007). Evidence that the hyaline cartilage phenotype can be made stable with improved approaches will be provided by long term studies on relevant animal models and, ultimately, in humans. 
Reviewer II: Did the authors look for bone formation in the in vivo implants?

Authors: The von Kossa staining revealed deposits of calcium in the subcutaneous implants of MSC+TGFloaded microspheres but not in those of MSC+unloaded microspheres (Fig. 8b). However, sectioning of the implants did not require a decalcification step, indicating that mature bone had not yet formed and that the neotissue was rather calcified cartilage. These data suggest that the vascularised subcutaneous environment is not adequate for stabilising the mature phenotype of cartilage, and is promoting hypertrophy, mineralisation and osteogenesis in the presence of a TGF- $\beta 3$ releasing scaffold. We further report evidences that the implants of MSC+TGF-loaded microspheres were themselves densely vascularised. We speculate that TGF- $\beta 3$ released by the scaffold, and probably vascular endothelial growth factor produced by hypertrophic chondrocytes (Gerber et al., 1999), were responsible for enhanced angiogenesis, which in turn is known to promote osteogenesis. Overall, these data indicate that although a TGF-loaded biomaterial is required for the formation of a cartilage-like tissue by MSC, it ends up in a calcified cartilage after ectopic subcutaneous implantation, similar to that found in the deep zone of articular cartilage, adjacent to subchondral bone. In this regard, formation of such calcified tissue may be limited to the deep zone after orthotopic implantation in a cartilage defect, respecting the natural organisation of this tissue (Steck et al., 2009), because the joint is subject to cycles of mechanical loading and to a hypoxic/avascular environment, which have been shown to increase chondrocyte anabolic activity and reduce hypertrophy (reviewed in Ramage et al., 2009 and Studer et al., 2012). Nevertheless, to increase the chance to form non-hypertrophic cartilage, one possibility will be to drastically reduce the amount of loaded TGF as mentioned in the discussion, since data from the literature suggest that mineralisation is due to high local levels of this factor (van Beuningen et al., 1994; Bakker et al., 2001, Zhen et al., 2013).

Reviewer II: What do you expect would be the fate of these implants with respect to hypertrophic chondrocyte formation once they run out of TGFbeta?

Authors: We believe that the fate of these implants is not only dependent on the release of TGF- $\beta 3$ but also on the subcutaneous environment, which is not suitable for the maintenance of a mature cartilage, as explained in the response to the first question. The subcutaneous implants releasing TGF- $\beta 3$ formed a cartilage which was hypertrophic and calcified, as shown by immunodetection of type X collagen and von Kossa staining, respectively. Thus, the continuous release of TGF- $\beta 3$ did not prevent this unwanted process. Hypertrophic differentiation may further increase once the TGF- $\beta 3$ reservoir is exhausted, but alternatively a dedifferentiation process may occur which will eventually lead to the formation of a fibrotic tissue. We are eager to answer this question in future studies aimed at investigating our approach in an animal model of a chondral defect. As explained in our answer to the preceding question, the chance of forming nonhypertrophic cartilage and its maintenance in the long term should be greatly increased in an orthotopic environment.

\section{Additional Reference}

Steinert AF, Ghivizzani SC, Rethwilm A, Tuan RS, Evans CH, Noth U (2007) Major biological obstacles for persistent cell-based regeneration of articular cartilage. Arthritis Res Ther 9: 213. 